Portland State University

PDXScholar

Dissertations and Theses

Dissertations and Theses

Winter 4-10-2018

\title{
Design Optimization for a CNC Machine
}

Alin Resiga

Portland State University

Follow this and additional works at: https://pdxscholar.library.pdx.edu/open_access_etds

Part of the Mechanical Engineering Commons

Let us know how access to this document benefits you.

\section{Recommended Citation}

Resiga, Alin, "Design Optimization for a CNC Machine" (2018). Dissertations and Theses. Paper 4257. https://doi.org/10.15760/etd.6141

This Thesis is brought to you for free and open access. It has been accepted for inclusion in Dissertations and Theses by an authorized administrator of PDXScholar. Please contact us if we can make this document more accessible: pdxscholar@pdx.edu. 
Design Optimization for a CNC Machine

by

Alin Resiga

A thesis submitted in partial fulfillment of the requirements for the degree of

\author{
Master of Science \\ in \\ Mechanical Engineering
}

Thesis Committee:

Sung Yi Chair

Faryar Etesami

Chien Wern

Portland State University

2018 


\begin{abstract}
Minimizing cost and optimization of nonlinear problems are important for industries in order to be competitive. The need of optimization strategies provides significant benefits for companies when providing quotes out for products. Accurate and easily attained estimates allow for less waste, tighter tolerances, and better productivity. The Nelder-Mead Simplex method with exterior penalty functions was employed to solve optimum machining parameters. Two case studies were presented for optimizing cost and time for a multiple tools scenario. In this study, the optimum machining parameters for milling operations were investigated. Cutting speed and feed rate are considered as the most impactful design variables across each operation. Single tool process and scalable multiple tool milling operations were studied. Various optimization methods were discussed. The Nelder-Mead Simplex method showed to be simple and fast.
\end{abstract}




\section{Biography}

Alin Resiga is a Master of Science candidate in the mechanical engineering department at Portland State University. He received a Bachelor of Science degree in Mechanical Engineering, from Portland State University in 2015. His senior capstone project was the Electro-Mechanical Nosecone Separation Mechanism. After earning his BS degree, he joined Intel Corporation. Currently he works in the technology and manufacturing group. 


\section{Acknowledgements}

The author wishes to express his sincere gratitude to his parents Valentina and Ioan

Resiga, his extended family, his advisor Dr. Sung Yi, his coworkers at Intel, his

friends, his girlfriend, Portland State University and the office administrators on the 4th floor. 


\section{Table of Contents}

Abstract i

Biography ii

Acknowlegdements iii

List of Tables

List of Figures vii

Acknowlegdements viii

Chapter 1: Introduction 1

Chapter 2: Previous work 2

2.1 Previous optimization methods . . . . . . . . . . . . 3

2.1.1 The Method of Feasible Direction . . . . . . . . . . . . . . . 3

2.1 .2 Genetic Algorithm . . . . . . . . . . . . . . . 4

2.1.3 Continuous Ant Colony Algorithm . . . . . . . . . . . . . . 5

2.1.4 Tabu search method . . . . . . . . . . . . . . . . 9 9

2.1 .5 Particle Swarm Optimization . . . . . . . . . . . . 10

Chapter 3: Nelder-Mead Simplex with exterior penalty 12

3.1 Nelder-Mead Flow Chart . . . . . . . . . . . . . . . . . . . 14

Chapter 4: Optimization model 17

4.1 Unit cost . . . . . . . . . . . . . . . . . . . . . . . 17

4.2 Unit time $\ldots \ldots \ldots \ldots \ldots$

4.3 Profit rate . . . . . . . . . . . . . . . . . . . . . . . . . . . 25

4.4 Constraints $\ldots \ldots \ldots \ldots$

4.4 .1 Power $\ldots \ldots \ldots \ldots \ldots$. . . . . . . . . . . . . . . . . . . . . 27

4.4 .2 Surface finish $\ldots \ldots \ldots \ldots$. . . . . . . . . . . . . . . . 28

4.4 .3 Cutting forces . . . . . . . . . . . . . . . . . 30

4.5 General equation . . . . . . . . . . . . . . . . . . 31

4.6 Case Study 1 . . . . . . . . . . . . . . . . . . . . . . . . . . . . . . . . 33

4.7 Case study 2 . . . . . . . . . . . . . . . . . . . . . . . . . . . . . . . . . . 41

Chapter 5: Results 45

5.1 Validating the objective equation . . . . . . . . . . . . . 45 
5.2 Validating the penalty function . . . . . . . . . . . . . . 46

5.3 Constraint violation . . . . . . . . . . . . . . . . . . . . . . . . . . . . 48

5.4 Optimal design variables: Case study 1 . . . . . . . . . . . . . . . . 49

5.5 Cost after each cut: Case study 1 . . . . . . . . . . . . . . . 50

5.6 Time after each cut: Case study 1. . . . . . . . . . . . . . . . 51

5.7 Sensitivity study . . . . . . . . . . . . . . . . . . . 52

5.8 Optimal design variables: Case study 2 . . . . . . . . . . . . . . 54

5.9 Cost after each cut: Case study 2 . . . . . . . . . . . . . . . . 55

5.10 Time after each cut: Case study 2 . . . . . . . . . . . . . 56

Chapter 6: Conclusion

Preface: Biography 59 


\section{List of Tables}

4.1 Parameters for Case Study 1[7]. . . . . . . . . . . . . . . . . . . . . 33

4.2 Constants for Case study 1[7].] . . . . . . . . . . . . . . . . . . . . . 34

4.3 Required machining operation Case study 1[7]. . . . . . . . . . . . . . 34

4.4 Tools data for Case study 1[7]. . . . . . . . . . . . . . . . . . . . . 36

4.5 Tools data parameters Case study 2. . . . . . . . . . . . . . 43

4.6 Required machining operation for Case study 2. . . . . . . . . . . . . 43

4.7 Tools data Case study 2. . . . . . . . . . . . . . . . . . . . . . 444

$5.1 \quad$ Validating the ability to calculate the correct cost unit $c_{u}$. . . . . . 45

5.2 Validating the ability to calculate the correct time unit $t_{u}$. . . . . . 46

$5.3 \quad$ Error from the original paper[7]. . . . . . . . . . . . . . 47

5.4 Power constraints are violated in the genetic methods for operation one and three. . . . . . . . . . . . . . . . . 48

5.5 Optimal design parameters for case study one. . . . . . . . . . . 50

$5.6 \quad$ Simplex beats handbook and method of feasible direction. . . . . . . 52

5.7 When the initial guess is set at a local minimum. . . . . . . . . . 53

5.8 Optimal design parameters for case study 2. . . . . . . . . . . . 54 


\section{List of Figures}

2.1 Flow chart of continuous ant colony method[1]. . . . . . . . . . . . 8

$2.2 \quad$ Distribution of ants for local and global search[1]. . . . . . . . . . . . 9 9

3.1 Nelder-Mead flow chart overview. . . . . . . . . . . . . . . . . 16

4.1 Drawing of Case study 1[7]. . . . . . . . . . . . . . . . . . 35

4.2 Case study 1: Operation one. . . . . . . . . . . . . . . . 37

4.3 Case study 1: Operation two. . . . . . . . . . . . . . . . . . . . 38

4.4 Case study 1: Operation three. . . . . . . . . . . . . . . . 39

4.5 Case study 1: Operation four. . . . . . . . . . . . . . . . . . . 40

4.6 Case study 1: Operation five. . . . . . . . . . . . . . . . 41

$4.7 \quad$ Drawing of case study $2.7 \ldots \ldots$. . . . . . . . . . . . . . 42

5.1 Cost after each operation in Case study 1. . . . . . . . . . . . . . . . 50

5.2 Time after each operation in Case study 1. . . . . . . . . . . . . . . . 51

5.3 Cost after each operation in Case study 2. . . . . . . . . . . . . . . . 55

5.4 Time after each operation in Case study 2. . . . . . . . . . . . . . . . 566 


\section{Nomenclature}

\begin{tabular}{|c|c|}
\hline$A$ & Chip cross sectional area $\left(\mathrm{mm}^{2}\right)$ \\
\hline$a, a_{\text {rad }}$ & Axial depth of cut, radial depth of cut (mm) \\
\hline$C$ & Constant in cutting speed equation \\
\hline$c a$ & Clearance angle of the tool (degrees) \\
\hline$C_{i}(i=1,2, \ldots 8)$ & Coefficients carrying constants values \\
\hline$c_{l}, c_{o}$ & Labour cost, overhead cost $(\$ / \mathrm{min})$ \\
\hline$c_{m}, c_{m a t}, c_{t}$ & $\begin{array}{l}\text { Machining cost, cost of raw material per part, cost of a } \\
\text { cutting tool }(\$)\end{array}$ \\
\hline$C_{u}$ & Unit cost $(\$)$ \\
\hline$d$ & Cutter diameter $(\mathrm{mm})$ \\
\hline$e$ & Machine tool efficiency factor (\%) \\
\hline$F$ & Feed rate $(\mathrm{mm} / \mathrm{min})$ \\
\hline$f, f_{o}$ & Feed rate, $(\mathrm{mm} /$ tooth $)$ optimum \\
\hline$F_{C}, F_{C(p e r)}$ & Cutting force, Permitted cutting force $(\mathrm{N})$ \\
\hline$F_{F}, F_{R}, F_{T}$ & $\begin{array}{l}\text { Feeding, radial and tangential forces resulting from all active } \\
\text { cutting teeth }(\mathrm{N})\end{array}$ \\
\hline$G, g$ & Slenderness ratio, exponent of slenderness ratio. \\
\hline$K$ & $\begin{array}{l}\text { Distance to be traveled by the tool to perform the operation } \\
(\mathrm{mm})\end{array}$ \\
\hline$K_{i}(i=1,2,3)$ & Coefficients carrying constant values \\
\hline$K_{p}$ & Power constant depending on the workpiece material $(\mathrm{kW})$ \\
\hline$l a$ & Lead (corner) angle of the tool $\left({ }^{\circ}\right)$ \\
\hline$m$ & $\begin{array}{l}\text { Number of machining operations required to produce the } \\
\text { product }\end{array}$ \\
\hline$N$ & Spindle speed $(\mathrm{rev} / \mathrm{min})$ \\
\hline$n$ & Tool life exponent (unitless) \\
\hline$P, P_{m}$ & Required power for the operation, motor power $(\mathrm{kW})$ \\
\hline$P_{r}$ & Total profit rate $(\$ / \mathrm{min})$ \\
\hline$Q$ & $\begin{array}{l}\text { Contact proportion of cutting edge with workpiece per } \\
\text { revolution (unitless) }\end{array}$ \\
\hline$R$ & $\begin{array}{l}\text { Sale price of the product excluding material, setup and tool } \\
\text { changing costs }(\$)\end{array}$ \\
\hline$R_{a}, R_{a(a t)}$ & $\begin{array}{l}\text { Arithmetic value of surface finish, and attainable surface } \\
\text { finish }(\mu \mathrm{m})\end{array}$ \\
\hline$S_{p}$ & Sale price of the product $(\$)$ \\
\hline$T$ & Tool life (min) \\
\hline$T_{u}$ & Unit time (min) \\
\hline$t_{m}, t_{s}, t_{t c}$ & Machining time, set-up time, tool changing time (min) \\
\hline$V, V_{o}$ & $\begin{array}{l}\text { Cutting speed, recommended by handbook, optimum } \\
(\mathrm{m} / \mathrm{min})\end{array}$ \\
\hline$w$ & Exponent of chip cross-sectional area (unitless) \\
\hline$W$ & Tool wear factor (unitless) \\
\hline$z$ & Number of cutting teeth of the tool \\
\hline
\end{tabular}




\section{Chapter 1: Introduction}

Establishing efficient machining parameters has been an important problem and is a consistent and difficult obstacle for operators to work on. Most operators use best known practices found in handbooks. Depth of cut, feed rate, and cutting speed have shown the greatest effects on the cost and time of the machining operations [2]. Depth of cut is usually predetermined by the workpiece geometry and operation sequence. The depth of cut requires the operator to choose a particular drill bit that is long enough to cut the whole operational part in one try. When the depth of cut is not long enough to cut the whole part, additional operations may be added to make up for the missing depth. The additional operation follows the same pattern but is done for the depth of the part is adequate to meet the requirements. The problem of determining the machining settings becomes reduced to selecting the proper cutting speed and feed rate combination. The drill bit is either long enough and doesn't need additional operations, or it is not. The cutting speed and feed rate has the greatest impact on the cost and time of the unit. Other settings have a much smaller impact but they are not changed because of the difficulty of changing such parameters. For example, the cost of labor does not change significantly from shop to shop inside a city, whereas the cutting speed and feed rate may vary significantly. 


\section{Chapter 2: Previous work}

Optimizing machining practices have been investigated by many researchers [1, 1, 8, . Much of the fundamental work has already been done in terms of objective function and sensitivity studies. Recently, the work is now directed towards how the optimal values are calculated and whether the validity of the constraints holds up. Some researches [1] have built on fundamental work[7] such as establishing the objective equation with parameters and case studies. Methods for optimization fall into three categories, derivative, non derivative and genetic. Genetic Algorithm methods are more complicated to understand. Some of these studies showed to have errors because they violated the constraints citebaskar. Other researchers [8] had showed that the Cuckoo Search Algorithm could produce better optimal design values than those obtained by Tolouei-Tad et all[7]. The Cuckoo Search Algorithm is in the same category as other Genetic Algorithms. However, the research paper [8] does not have the input design values. It is difficult to compare how accurate their findings [8] were to the original paper[7].

The Genetic Algorithm approach has become a popular method of solving optimization problems due to not requiring a derivative. Genetic Algorithms have been designed to with the intent to not get stuck at local minimums. Genetic Algorithms tend to have wider range of testing by testing in the feasible range and infeasible range. A wider range of testing leads to a better method for comparing local minimums to a global minimum. The intent of Genetic Algorithms is they will be helpful 
in naturally complex problems such as CNC machining, where the values are especially difficult to differentiate. Several researchers have reached different optimal values [1, 7, 8], although it is easy to figure out which inputs lead to the optimum. It is not easy to figure out which constraints are violated, which assumptions are wrong and which machining practices are missed. There were errors in the original paper [7] with the power constraints and the surface finish. However, such errors were discussed in either reference papers[1] [8]. The constraints errors are discussed more in the 5.2 section of the present study. The reference papers[1] [8] did not address the power and surface finish constraints.

\subsection{Previous optimization methods}

\subsubsection{The Method of Feasible Direction}

The method of feasible direction used by [7] is a derivative method. The method finds the derivative of the objective function and then finds the greatest rate of change. The greatest rate of change predicts where the global minimum is. The method starts out with an initial guess $X^{0}$ as recommended by the handbook. Each iteration in the search direction is carried out as 


$$
X^{q}=X^{q-1}+a^{*} S^{q}
$$

where $q$ is the iteration number and $S$ is the vector search direction in the design space. The Scalar $a^{*}$ defines the distance of move in the search direction. It is important to find the search direction without violating the constraints. Selecting the initial point to the handbook recommendation cuts down on the number of iterations. Some things

to consider are that $X^{q-1}$ is inside the feasible region the gradient otherwise it should stop. If $X^{q-1}$ is on the boundary of one or more constraints maximize $\beta$ according to $\nabla F(X) S+\beta \leq 0$ and $\nabla g_{j}(X) S+\theta \beta \leq 0$ by calculating $S^{q}$ with linear programming. This method benefits from having high-speed programming language such as Fortran because iterations are costly.

\subsubsection{Genetic Algorithm}

The Genetic Algorithm (GA) method[1] is a more complicated method than the method of feasible direction. However, the GA method has qualities that are reminiscent of a shotgun approach where the spread is very wide. The GA method emulates the selection of natural genetics. All the same principles that exist in chromosome pairing exist in this Algorithm. Various mutations of inputs in the objective function 
try to survive in a race to the global minimum.

1. It begins by choosing a code to represent problem parameter, a selection operator, a crossover operator and a mutation operator. Choose population size $\mathrm{N}$, crossover probability $p_{c}$ and mutation probability $p_{m}$. Initialize a random population of strings of size 10 . set it $=0$.

2. Evaluate each string in the population.

3. if $i t \geq i t_{\max }$ (or) if other termination criteria is satisfied, terminate.

4. Perform reproduction on the population.

5. Perform crossover on the random pairs of string.

6. Perform bit-wise mutation.

7. Evaluate strings in the new population. set $i t=i t+1$ and go to step 3 .

\subsubsection{Continuous Ant Colony Algorithm}

Similar to the Genetic Algorithm, the Continuous Ant Colony Algorithm (CACO) tries to emulate nature. The Continuous Ant Colony Algorithm (CACO) has a global search and a local search. The global search has three parts- Random Walk, Mutation and Trail Diffusion. Random walk has $90 \%$ of the solution randomly chosen in the feasible range. The inferior solutions are replaced with randomly selected solution from superior solutions. Mutations occurs after the random walk step occur. In the mutation step, the possible solutions are randomly add or subtract a value to each variable of the newly created solutions. The solutions are part of the inferior region 
with a probability equal to a suitable defined mutations probability.

$$
\Delta(T, R)=R\left(1-r^{(1-T) b}\right)
$$

where $r$ is a random number from [0.1]. $\triangle$ is the rate of change in variables of the variables of $T$ and $R . \quad R$ is a maximum step size. $T$ is a ratio of the current iteration number to that of the total number of iterations. $b$ is the positive parameter controlling the degree of nonlinearity [1]. Lastly, trail diffusion applies to inferior solutions that were not considered during the random walk and mutation stages. The two parent's weight are selected at random. The variables of the children's positions can have any combination of the parent's solutions.

$$
x(\text { child })=(\alpha) x_{i}\left(\text { parent }_{1}\right)+(1-\alpha) x_{i}\left(\text { parent }_{2}\right)
$$

where $\alpha$ is the weighted uniform random variable that predicts how much of each parent's input is carried to the child. $\alpha$ variable ranges from 0 to $1.1-\alpha$ is set up so the second parent will make up the remainder. For local search the region $i$ is selected with the probability equation. 


$$
P_{i}(t)=\frac{\tau_{i}(t)}{\sum_{i=t}^{m} \tau_{i}(k)(t)}
$$

where $P_{i}(t)$ is the probability. $i$ is the region index and $\tau_{i}(t)$ is the pheromone trail on region $i$ at time $t$. Once the probability is selected, then the ant moves through a short distance. The short distance is a finite random increment. If the fitness value improves, the direction of movement is retained. The design variables are continuous values and subject to the limit available. In the continuous algorithm, the pheromone values decrease each iteration by

$$
\tau_{i}(t+1)=\rho
$$

where $\rho$ is the evaporation rate. The evaporation rate is assumed to be 0.2 on a trial basis and $\tau_{i}(t)$ is the trail associated with solutions at time $t$. 


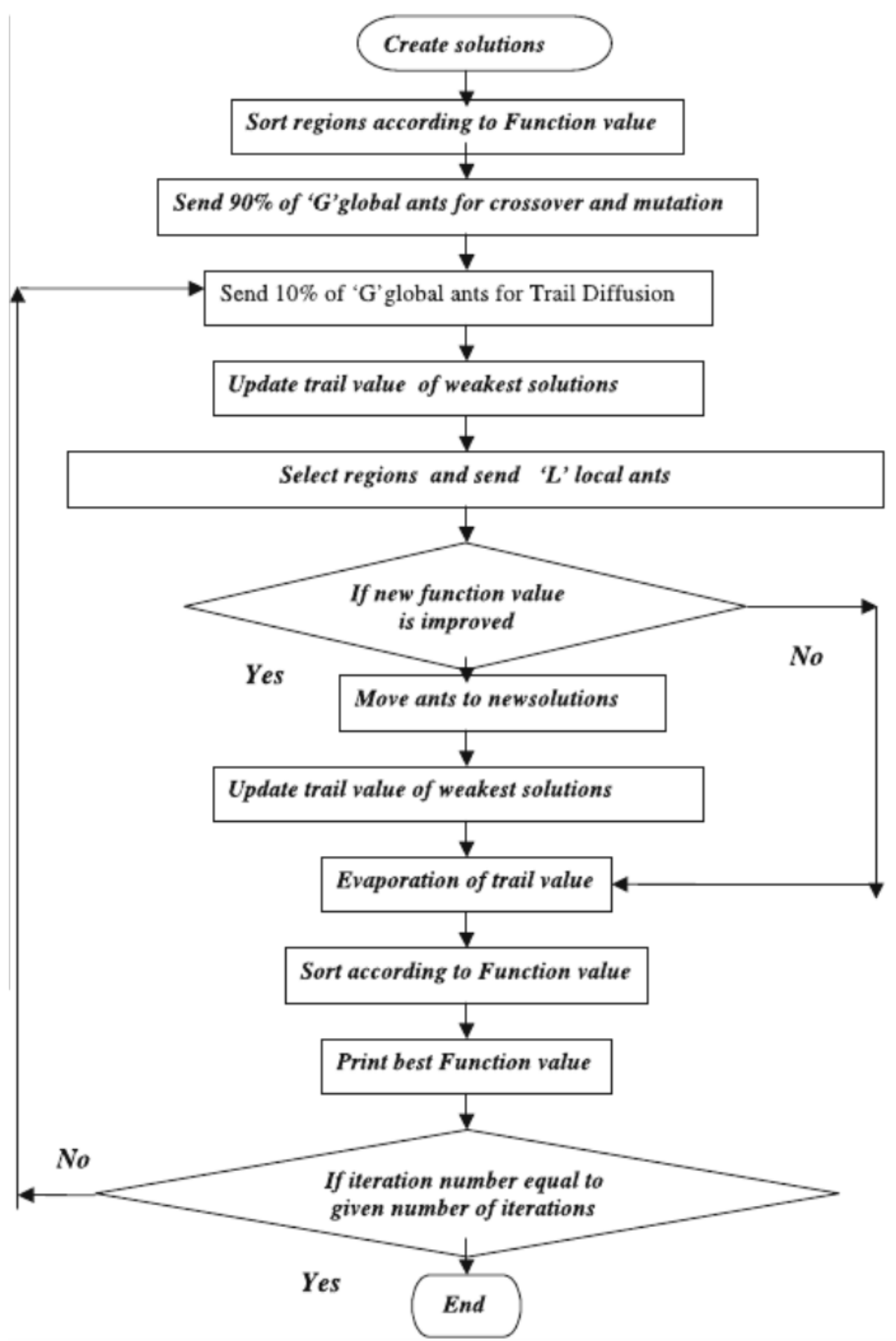

Figure 2.1: Flow chart of continuous ant colony method[1]. 


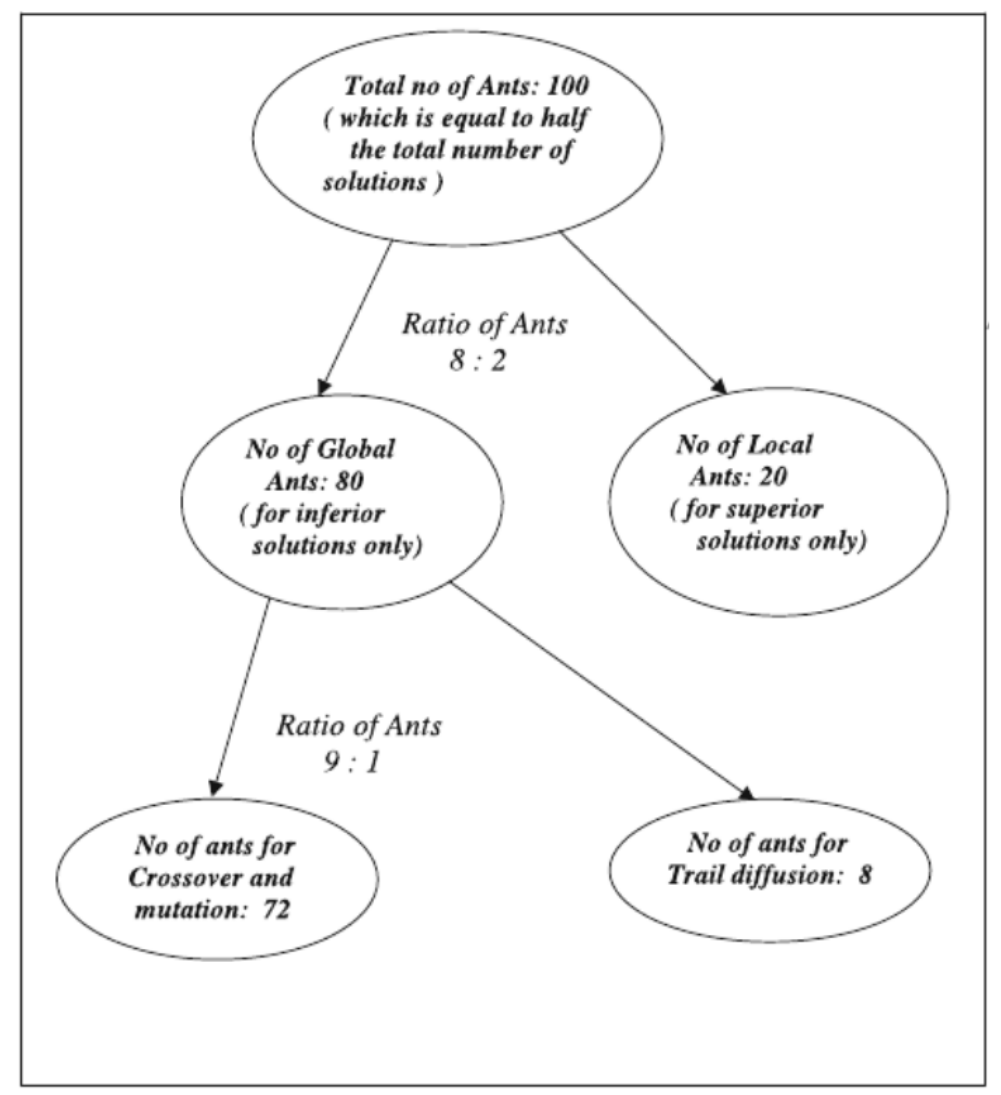

Figure 2.2: Distribution of ants for local and global search[1].

\subsubsection{Tabu search method}

The Tabu search method is part of the group of Genetic Algorithms. The design variables are coded as string in binary and the strings increase in digits based on how accurate the desired answer is. The initial solution is selected using a random function. The termination is selected by the user choice. The Tabu search method will run as many iterations as stated. 
Then a neighborhood is determined with a subset of another neighborhood[1]. At this point the neighborhoods are compared to select the best profit rate to maximize. The best seed is chosen and updated inside the Tabu list. If the next iteration is better than the best. Then the previous iteration is set the next iteration as the best. The process begins again with a new value. Terminatition is if it passes the initial set iterations count[1]. Without a termination value to compare it the converging solution it becomes difficult to know when to stop. One idea would be to stop when the same optimal input lead to same outputted solution. However, it could lead to a solution that is always progressively better than the previous iteration.

\subsubsection{Particle Swarm Optimization}

The Particle Swarm Optimization (PSO) method works by following another method seen in nature, bird flocking. First, each particle is initialized. Then calculate the fitness value of each particle. If the fitness values is better than the best fitness value in history, set the current value as the best. [1] Choose the particle with the best fitness value of all time, and then the particles become gbest[]. For each particle, the particle velocity can be calculated as 


$$
\begin{array}{r}
v[]=v[]+c_{1} \operatorname{rand}()\left(\text { pbest }[]-[\text { present }[])+c_{2} \operatorname{rand}()(\text { gbest }[]-\text { present }[])\right) \\
\operatorname{present}[]=\operatorname{present}[]+v[]
\end{array}
$$

where $v[]$ is the particle velocity, present [] is the current particle solution and $\operatorname{rand}[]$ is a random number between $(0,1) \cdot c_{1}, c_{2}$ are learning factors. Particle velocities in each dimension are limited to a maximum velocity. If the sum of the acceleration causes the velocity to exceed the maximum velocity, then the constraint specified for the user is limited to the maximum. In other words, the velocity is stopped at velocity maximum or stopped at the maximum constraint. 


\section{Chapter 3: Nelder-Mead Simplex with Exterior Penalty}

The Nelder-Mead Simplex method can be used to find the minimum dollar amount of the objective function in a multidimensional space. The Nelder-Mead Simplex method can be used for other variables than money. The method is applied to nonlinear optimization problems for which the derivatives may not be known. The Nelder-Mead Simplex method is useful when the derivative equations become costly to compute every iteration. In this present study, the design variables are limited to fourteen terms. Increasing the design variables in the Nelder-Mead Simplex method is straightforward. The Nelder-Mead method works by creating a large range of values, marking the best, worst and second worst values.

The exterior penalty function adds value to the objective function when the constraints are violated. The penalty function prevents the Nelder-Mead Simplex algorithm from going down to negative infinity. If a constraint is violated the objective function starts to increase due to the penalty function. If the objective function is increased, the Nelder-Mead Simplex algorithm will move away from that particular value. The Nelder-Mead Simplex method uses four methods to converge the Simplex triangle into a solution. These four methods are Reflection, Expansion, Contraction, and Shrink [5]. Reflection flips the triangle's top corner to the other side due to a better group of solutions being shown on the other side. Expansion extends one of the legs in the triangle so it is able to cover a better best-case solution. Contraction moves one of the legs inside the triangle, which eliminates bad solutions are shown. 
Lastly, shrinking is when each of the points become closer to the best-case.

The penalty value becomes an important setting that needs to be fine-tuned. The magnitude of scale for the objective function and penalty function should match each other. The magnitude of scale can be altered by changing the penalty value. The penalty value is changed to what makes the penalty function have the same magnitude of scale as the objective function. Anything less than the same magnitude will result in the Simplex triangle overstepping the optimal values. Anything too large will also result in a centroid of the Simplex triangle being out of the feasible range. If the centroid moves outside of the feasible range, the Simplex triangle will not recover. The penalty value becomes more difficult to fine tune for multiple constraints. If there are multiple constraints violated at the same time, the magnitude of scale for the penalty function is going to be significantly larger than if only one constraint is violated. It is more difficult to pick the correct penalty value if the objective equation has a lot of design values. In the present study, the penalty value was set to 1000 . Each set of design variables is restricted to its own constraints. The termination value is determined from equation 3.1 .

Once the penalty value is set, the next step becomes setting the Simplex parameters. Optimizing the parameters of the Nelder-Mead method become its own optimization problem. Most Nelder-Mead Simplex parameters tend to cluster the around following points called universal points $\alpha=1, \gamma=2, \rho=0.5$, and $\sigma=0.5$ [4. Although the parameters tend to cluster to particular values, each problem needs fine tuning. One way of approaching the fine tuning of the Nelder-Mead parameters 
is to create a for loop for each parameter with an upper limit and a lower limit. The for loop is intended to test each setting to see how the increase value will affect the optimal design values. The limits for the for loops is usually the universal point plus or minus $15 \%$. The method for setting the limits is called the Resiga method. For simple problems fine tuning the Simplex parameter is easy because computation time is small. For more complicated objective functions, the step between the limit is larger. Smaller steps will reduce the computation time.

$$
\epsilon=\sqrt{\frac{1}{N+1} \sum_{i=1}^{N+1}\left(x_{i}-x_{o}\right)^{2}}
$$

\subsection{Nelder-Mead Flow Chart}

Like most optimization problems, the initial estimate is set to a value inside the feasible range. The feasible range is where the constraints are not violated. There is an initial step that is done in a positive direction and negative direction for each design variables for each operation. After each possible answer is calculated, a Simplex triangle is created from these possible answers.

A Simplex triangle is a group of possible answers that holds an optimal solution. The Simplex triangle has two times the number of design variables times the number of operations. In Case study 1, there were twenty points in the Simplex triangle. If the 
objective equation is in two dimension, the Simplex triangle is a true triangle. If there are more than three design variables the Simplex triangle becomes a polymorphic shape.

At this point, the worst case, second worst case, and best cases is defined in the Simplex triangle. The Simplex triangle is fed through the flowchart below that is contracted, reflected, expanded and finally shrink, until the termination value is satisfied. Any value that is violates a constraint will have an additional value tacked onto it. 


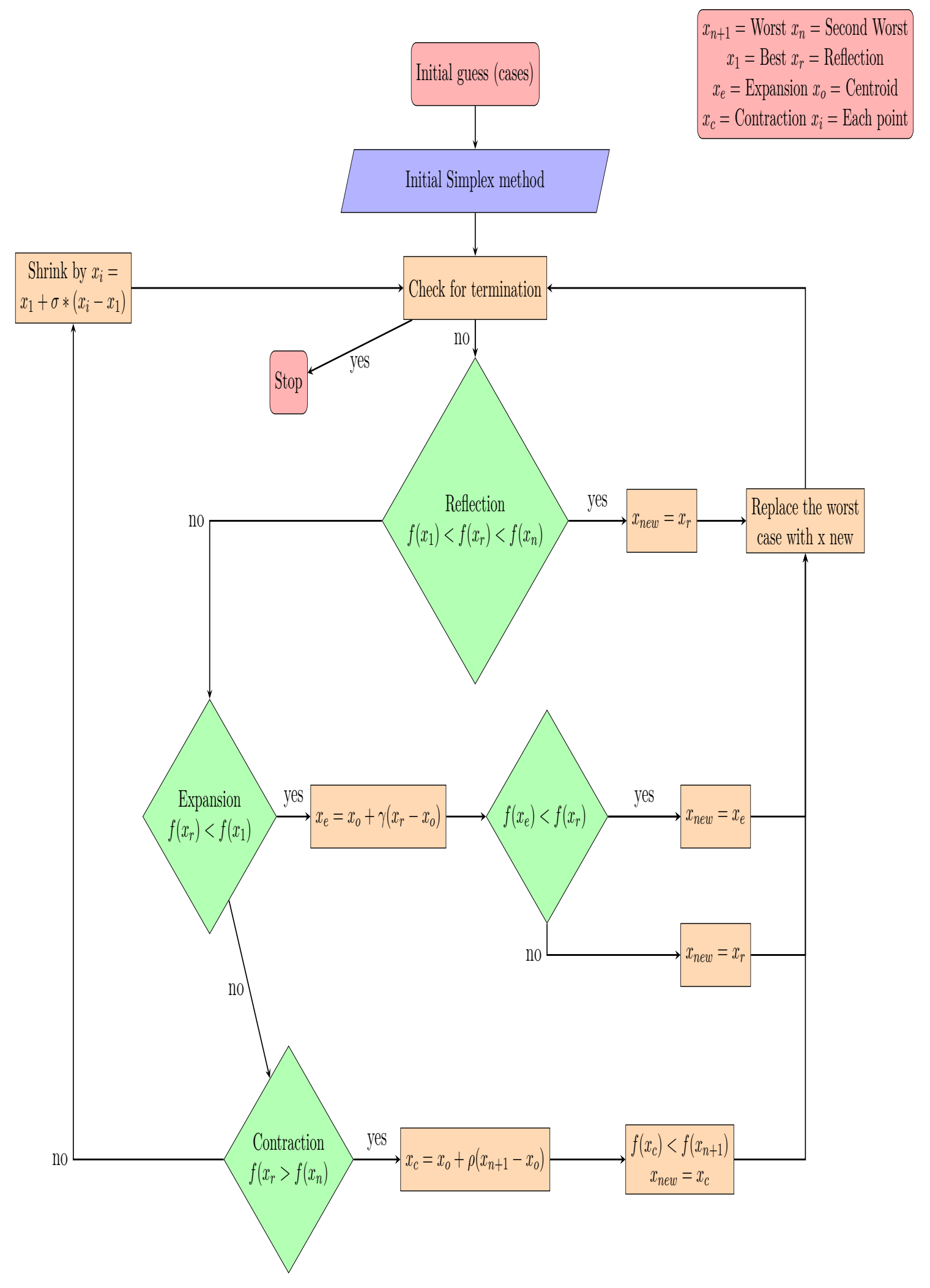

Figure 3.1: Nelder-Mead flow chart overview. 


\section{Chapter 4: Optimization model}

There are two ways to maximize profit, minimize the cost per unit or the time per unit [7]. Having only cost minimized or time will result in a solution that is not optimal as the overall goal is to maximize the profit. Money is a byproduct of both dollar amount and time spent. The income received for a unit will not change even if the design variables change. However, the profit may indeed change if cost or time spent is reduced. A simple first attempt equation is

$$
P_{r}=\frac{S_{p}-c_{u}}{t_{u}}
$$

The following sections will discuss how to cost per unit and time per unit equations are modeled and what assumptions were made.

\subsection{Unit Cost}

The cost of designing a model is broken into four separate groups: the cost of raw material, set-up cost, machining cost and tool changing cost. 


$$
c_{u}=c_{m a t}+\left(c_{l}+c_{o}\right) t_{s}+\left(c_{l}+c_{o}\right) t_{m}+\left(c_{l} t_{t c}+c_{t}+c_{o} t_{t c}\right) \frac{t_{m}}{T}
$$

Equation 4.2 is for a single tool. However this can be extended to $i$-th tool. $i$ is the amount of operations done. Through a series of equations, machine time for milling operations can be determined by

$$
t_{m}=\frac{K}{F}=\frac{t_{K}}{f z N} \text { with } N=\frac{1000 V}{\pi d}
$$

is simplified to:

$$
t_{m}=\frac{\pi d K}{1000 V f z}
$$

All of the factors that go into the tool life can be grouped together in a constant such as 


$$
K_{1}=\frac{\pi d K}{1000 z}
$$

where this could apply to any tool.

$$
t_{m}=K_{1} x_{1}^{-1} x_{2}^{-1}
$$

Kronenberg[3] was able to find the relation of tool life relation with dimensional analysis as

$$
V=\frac{C(G / 5)^{g}}{A^{w}\left(\frac{T}{60}\right)^{n}}
$$

The values for $\mathrm{C}$ and $\mathrm{n}$ depend upon the quality of the tool and hardness of the workpiece of the material. The better the quality, the higher value of $\mathrm{C}$. The case study concluded HSS tools have 0.15 and carbide tools had an $\mathrm{n}$ value of 0.3 . This tool life equation takes more variables into account than the one present in this present paper. The work proposed by Kronenberg[3] is used as an estimate for how often the 
tool needs replacement.

$$
T=60\left[\frac{C(G / 5)^{g}}{A^{w} V}\right]^{\frac{1}{n}}
$$

The equation is now solved for tool life through experimental methods. The cutting edge cannot be in contact with the workpiece the whole time, a proportion value $Q$ is required to account for the lack of cutting. The proportional value is also taken into account when the using half of the radial depth of cut.

$$
T=\frac{60}{Q}\left[\frac{C(G / 5)^{g}}{A^{w} V}\right]^{\frac{1}{n}}
$$

Substituting the values of slenderness ratio $G=\frac{a}{f}$ and the chip cross-sectional area to $A=a f$ :

$$
T=\frac{60}{Q} C^{\frac{1}{n}} 5^{\frac{-g}{n}} a^{\frac{g-w}{n}} V^{\frac{-1}{n}} f^{\frac{-(w+g)}{n}}
$$

Parallel to the $K_{1}$, which combines all the tool coefficients without the design vari- 
ables, into a single value. The tool life impact coefficients is combined to $K_{2}$.

$$
K_{2}=\frac{60}{Q} C^{\frac{1}{n}} 5^{\frac{-g}{n}} a^{\frac{g-w}{n}}
$$

Then tool life equations is simplified to only require the $K_{2}$ with the design variables.

$$
T=K_{2} V^{\frac{-1}{n}} f^{\frac{-(w+g)}{n}}
$$

$K_{2}$ is related the coefficients of cost of the tool life and $K_{1}$ is related the machine time, $\frac{t_{m}}{T}$ is analogous $\frac{K_{1}}{K_{2}} \cdot \frac{K_{1}}{K_{2}}$ is simplified to $K_{3} . K_{3}$ is considered a depreciation variable tasked with modeling how much impact one single operation has on the tool life.

$$
\begin{array}{r}
\frac{t_{m}}{T}=K_{3} V^{\frac{-1}{n}-1} f \frac{-(w+g)}{n}-1 \\
K_{3}=\frac{K_{1}}{K_{2}}
\end{array}
$$


$K_{1}$ and $K_{3}$ are plugged into the general cost per unit equation 4.2 .

$$
\begin{array}{r}
c_{u}=c_{\text {mat }}+\left(c_{l}+c_{o}\right) t_{s}+\left(c_{l}+c_{o}\right) K_{1} x_{1}^{-1} x_{2}^{-1}+ \\
\left(c_{l} t_{t c}+c_{t}+c_{o} t_{t c}\right) K_{3} V^{\frac{-1}{n}-1} f^{\frac{-(w+g)}{n}-1}
\end{array}
$$

Equation 4.15 is defined for only a single tool. This is the case for production lines where machining of each feature is devoted to a particular machine. In single-tool operation tool changing time is a function of the ratio of machining time to tool life. In the case of multi-tool operations, tool changing time for each tool used is considered regardless of this ratio. Equation 4.15 can be extended it to the $i$-th term up to $m$ operations. When more machines are taken into consideration equation 4.15 changes to equation 4.16 .

$$
\begin{array}{r}
c_{u}=c_{m a t}+\left(c_{l}+c_{o}\right) t_{s}+\sum_{i=1}^{m}\left(c_{l}+c_{o}\right) K_{1_{i}} V_{i}^{-1} f_{i}^{-1}+ \\
\sum_{i=1}^{m} c_{t_{i}} K_{3_{i}} V_{i}^{\frac{-1}{n_{i}}-1} f_{i}^{\frac{-(w+g)}{n_{i}}-1}+\sum_{i=1}^{o}\left(c_{l}+c_{o}\right) t_{t c_{i}}
\end{array}
$$

where $t_{t c_{i}}$ is the time spent changing tools and $c_{t_{i}}$ is the cost of machining. $o$ is the number of tools. The equation is simplified more so there is only the design variables: 


$$
c_{u}=C_{1}+\sum_{i=1}^{m} C_{2_{i}} V_{i}^{-1} f_{i}^{-1}+\sum_{i=1}^{m} C_{3_{i}} V_{i}^{\frac{-1}{n_{i}}-1} f_{i}^{\frac{-(w+g)}{n_{i}}-1}+\sum_{i=1}^{o} C_{4_{i}}
$$

where $C_{1}$ is the cost of setting up the tools. $C_{2_{i}}$ is the cost of the actual work. $C_{3_{i}}$ is the cost of doing the actual work over the lifetime of the tool, or depreciation. Finally $C_{4_{i}}$ takes into account the cost of switching tools. Out of the equations above only $C_{2_{i}}$ and $C_{3_{i}}$ have design variables. Therefore, for optimization purposes, $C_{1}$ and $C_{4_{i}}$ can be discarded when creating the objective equation. $C_{1}$ and $C_{4_{i}}$ are important to finding the overall cost but not important to optimization.

$$
c_{m_{i}}=\sum_{i=1}^{m} C_{2_{i}} V_{i}^{-1} f_{i}^{-1}+\sum_{i=1}^{m} C_{3_{i}} V_{i}^{\frac{-1}{n_{i}}-1} f_{i}^{\frac{-(w+g)}{n_{i}}-1}
$$

where $c_{m_{i}}$ is the machining cost per operation. Equation 4.18 does not include the cost of setting up and swapping tools. $c_{m_{i}}$ is a nonlinear equation.

\subsection{Unit Time}

The unit time for a single tool is defined by: 


$$
t_{u}=t_{s}+t_{m}+t_{t c} \frac{t_{m}}{T}
$$

The solution for $t_{m}$ and $\frac{t_{m}}{T}$ have already been derived in Unit cost section.

$$
t_{u}=t_{s}+\sum_{i=1}^{m} K_{1_{i}} V_{i}^{-1} f_{i}^{-1}+t_{t c} K_{3} V^{\frac{-1}{n}-1} f^{\frac{-(w+g)}{n}}-1
$$

and for multiple tools then it becomes:

$$
t_{u}=t_{s}+\sum_{i=1}^{m} K_{1_{i}} V_{i}^{-1} f_{i}^{-1}+\sum_{i=1}^{o} t_{t c_{i}}
$$

The only terms that have the design variables are the $t_{m}$, all the other terms cannot be optimized.

$$
t_{m_{i}}=\sum_{i=1}^{m} K_{1_{i}} V_{i}^{-1} f_{i}^{-1}
$$

where $t_{m_{i}}$ is the machining time per operation. 


\subsection{Profit Rate}

For a single tool, the profit rate $P_{r}$ can be defined:

$$
P_{r}=\frac{S_{p}-c_{u}}{t_{u}}
$$

For any tool, it become to the $i$-th term

$$
P_{r_{i}}=\frac{R_{i}-c_{m_{i}}}{t_{m_{i}}}
$$

where

$$
\begin{gathered}
R_{i}=R \frac{t_{m_{i}}}{t_{m}} \\
R=S_{p}-\left(C_{1}+\sum_{i=1}^{o} C_{4_{i}}\right)
\end{gathered}
$$

where $o$ is the number of tools. 


$$
\begin{gathered}
c_{m_{i}}=\sum_{i=1}^{m} C_{2_{i}} V_{i}^{-1} f_{i}^{-1}+\sum_{i=1}^{m} C_{3_{i}} V_{i}^{\frac{-1}{n_{i}}-1} f_{i}^{\frac{-(w+g)}{n_{i}}-1} \\
t_{m_{i}}=\sum_{i=1}^{m} K_{1_{i}} V_{i}^{-1} f_{i}^{-1}
\end{gathered}
$$

The objective equation becomes:

$$
f(x)=\frac{R_{i}-\left[\sum_{i=1}^{m} C_{2_{i}} x_{1_{i}}^{-1} x_{2_{i}}^{-1}+\sum_{i=1}^{m} C_{3_{i}} x_{1_{i}}^{\frac{1}{n}-1} x_{2_{i}}^{\frac{w+g}{n}-1}\right]}{\sum_{i=1}^{m} K_{1_{i}} x_{1_{i}}^{-1} x_{2_{i}}^{-1}}
$$

where $x_{1_{i}}=V_{i}$ and $x_{2_{i}}=f_{i}$

\subsection{Constraints}

In practice, possible range of cutting speed and feed rate is limited by the following constraints but there is more possible.

- Maximum machine power.

- Surface finish requirement.

- Maximum cutting force permitted by the rigidity of the tool.

- Available feed rate and spindle speed on the machine tool. 
- Maximum heat generated by cutting.

In this particular study, heat generated by the cutting was captured inside the tool life equation from $c_{u}$, specifically in $C_{3_{i}}$.

\subsubsection{Power}

The power equation is explained in equation 4.30 .

$$
P=\frac{0.78 K_{p} W z a_{\text {rad }} a}{60 \pi d e} V f^{0.8}
$$

The machining parameters are selected to use maximum machine power. The required machining power should not exceed available motor power. Therefore, the power constraint is rewritten as:

$$
C_{5} V f^{0.8} \leq 1
$$


where

$$
C_{5}=0.78 K_{p} W z a_{\text {rad }} \frac{a}{60 \pi d e P_{m}}
$$

\subsubsection{Surface Finish}

The arithmetic value of surface finish in plain milling be represented by:

$$
R_{a}=318 \frac{f^{2}}{4 d}
$$

and for face milling:

$$
R_{a}=318 \frac{f}{\tan (l a)+\cot (c a)}
$$

The required surface finish $R_{a}$ must not exceed the maximum attainable surface finish $R_{a(a t)}$ under the conditions. Therefore, the surface finish for end milling becomes:

$$
C_{6} f^{2} \leq 1
$$


where

$$
C_{6}=\frac{318(4 d)^{-1}}{R_{a(a t)}}
$$

and for face milling,

$$
C_{7} f \leq 1
$$

where

$$
C_{7}=\frac{318(\tan (l a)+\cot (c a))^{-1}}{R_{a(a t)}}
$$

Although $C_{6}$ and $C_{7}$ are separate equation only one of them is enacted depending if the operation is a face mill or an end mill. 


\subsubsection{Cutting Forces}

The total cutting force applied to the cutting tool in a milling operation is a result of tangential, feed and radial forces:

$$
F_{C}=\left(F_{T}^{2}+F_{F}^{2}+F_{R}^{2}\right)^{1 / 2}
$$

These force values are determined from equation 4.39 due [7] to calculating the forces experimentally. It is difficult to create a single equation that calculates the cutting force because some measurements are far too difficult to measure. Difficult factors that go into cutting forces is the tool's deflection, chatter, chip geometry and fluid dynamic equations. However, it instead is approximated with equation 4.40 for each direction of the force.

$$
F_{T}=K_{c} a f
$$

The $K_{c}$ value is found tabular. The total cutting force $F_{C}$ resulting from the machining operation must not exceed the permitted cutting force $F_{C(p e r)}$. The permitted cutting force for each tool is its maximum limit for cutting forces. Therefore, the 
cutting force constraint becomes:

$$
C_{8} F_{C} \leq 1
$$

where

$$
C_{8}=l / F_{C(p e r)}
$$

\subsection{General equation}

The objective equation is the terms, which involve the design variables. The objective equation is the equation being optimized. All other parameters not captured below do not affect the overall setting of the design variables. The objective equation is defined as:

$$
f(x)=\frac{R_{i}-\left[\sum_{i=1}^{m} C_{2_{i}} x_{1_{i}}^{-1} x_{2_{i}}^{-1}+\sum_{i=1}^{m} C_{3_{i}} x_{1_{i}}^{\frac{1}{n}-1} x_{2_{i}}^{\frac{w+g}{n}-1}\right]}{\sum_{i=1}^{m} K_{1_{i}} x_{1_{i}}^{-1} x_{2_{i}}^{-1}}
$$

where $x_{1_{i}}=V_{i}$ and $x_{2_{i}}=f_{i}$.

The objective equation is subject to: 


$$
\begin{array}{r}
g_{1}(x)=C_{5} x_{1} x_{2}^{0.8}-1 \leq 0 \\
g_{2}(x)=C_{6} x_{2}^{2}-1 \leq 0 \text { for end milling } \\
g_{2}(x)=C_{7} x_{2}-1 \leq 0 \text { for face milling } \\
g_{3}(x)=C_{8} F_{c}-1 \leq 0 \\
x_{1} \geq 0 x_{2} \geq 0
\end{array}
$$

The equations from 4.44 are combined together with the Penalty value. If the constraint is violated, a penalty value is multiplied to the equation it had violated. The new objective function is constructed by adding the constraints with the penalty function:

$y(x)=\sum_{i=1}^{m}\left[k_{p}(i) g_{1}(x, i)+k_{p}(i) g_{2}(x, i)+k_{p}(i) g_{3}(x, i)+k_{p}(i) x_{1}(i)+k_{p}(i) x_{2}(i)\right]$

where each term inside the bracket is single column matrix for every operation.

$$
k_{p}=0 \| 1000
$$


The overall equation is now the objective function plus any Penalty value that occurs from violating the constraint $F(x)=f(x)+y(x) . x$ is a 2 -by-m matrix, where $\mathrm{m}$ is the number of operations and 2 is the number of design variables per operation. If the objective equation includes the depth of cut, the $x$-matrix would become a 3-by-m.

\subsection{Case Study 1}

Case study 1 is from the original paper [7] as an example to compare results between the Nelder-Mead Simplex method and other methods. Below, there is the set parameters in Table 4.2 which sets up the cost and tool life parameters. The representation of the unit is capture in Figure 4.1 as well as the operational cuts and the machine parameters in Tables 4.3 and 4.4 .

Table 4.1: Parameters for Case Study 1[7].

Machine tool data:

Type: Vertical CNC milling machine $P_{m}=8.5 \mathrm{~kW}, e=95 \%$

Material data:

Quality: 10L50 leaded steel. Hardness $=225$ BHN 
Table 4.2: Constants for Case study 1[7].

\begin{tabular}{lll}
\hline$S p$ & $=\$ 25$ \\
$c_{\text {mat }}$ & $=\$ 0.50$ \\
$c_{o}$ & $=$ & $\$ 1.45$ per min \\
$c_{1}$ & $=$ & $\$ 0.45$ per min \\
$t_{s}$ & $=$ & $2 \mathrm{~min}$ \\
$t_{c t}$ & $=$ & $0.5 \mathrm{~min}$ \\
$C$ & $=$ & 33.98 for HSS tools \\
$w$ & $=$ & 0.28 \\
$C$ & $=$ & 100.05 for carbide \\
$K_{p}$ & $=$ & tool \\
$W$ & $=$ & 1.1 \\
$n$ & $=$ & 0.15 for HSS tools \\
$n$ & $=$ & 0.3 for carbide tool \\
$g$ & $=$ & 0.14 \\
\hline
\end{tabular}

Table 4.3: Required machining operation Case study 1[7].

\begin{tabular}{clcrrr}
\hline $\begin{array}{c}\text { Operation } \\
\text { No. }\end{array}$ & Operation & $\begin{array}{c}\text { Tool } \\
\text { Number }\end{array}$ & $a(\mathrm{~mm})$ & $K(\mathrm{~mm})$ & $R_{a}(\mu \mathrm{m})$ \\
\hline 1 & Face milling & 1 & 10 & 450 & 2 \\
2 & Corner milling & 2 & 5 & 90 & 6 \\
3 & Pocket milling & 2 & 10 & 450 & 5 \\
4 & Slot milling & 3 & 10 & 32 & - \\
5 & Slot milling & 3 & 5 & 84 & 1 \\
\hline
\end{tabular}



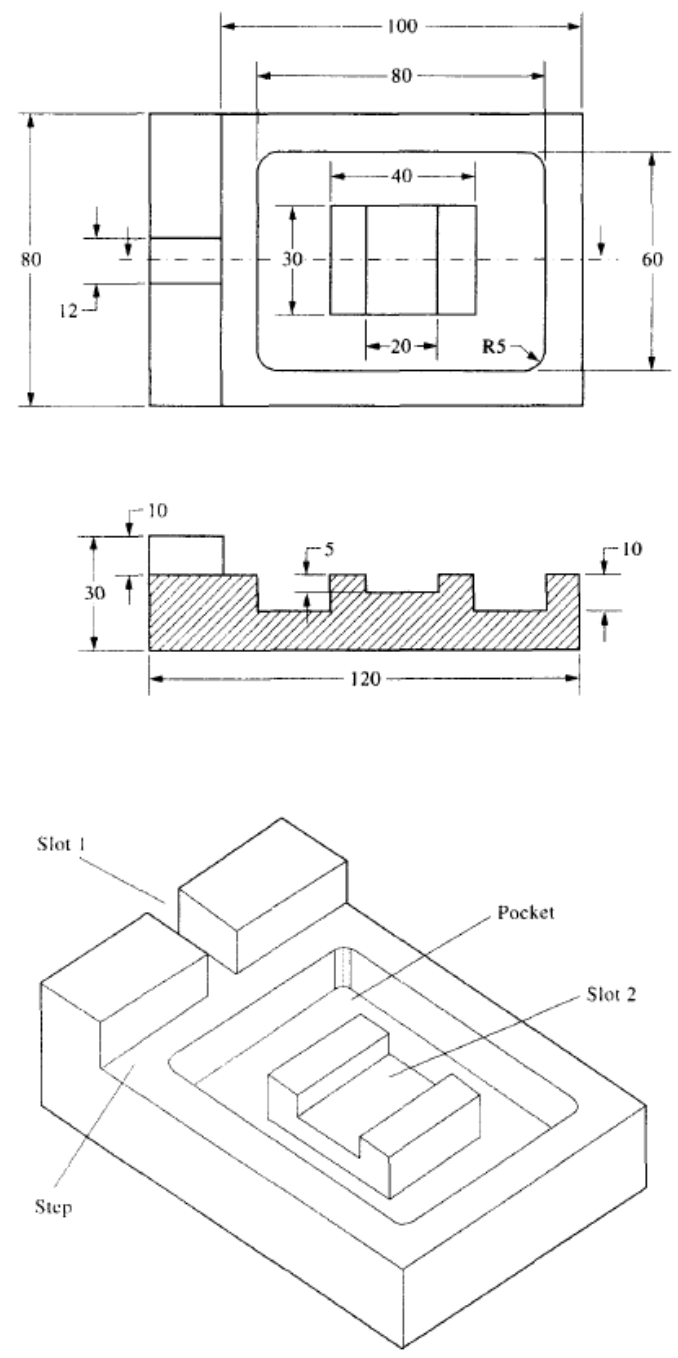

Figure 4.1: Drawing of Case study 1[7]. 
Table 4.4: Tools data for Case study 1[7].

\begin{tabular}{cccccccrcrrr}
\hline $\begin{array}{c}\text { Tool } \\
\text { No }\end{array}$ & $\begin{array}{c}\text { Tool } \\
\text { Type }\end{array}$ & Quality & $\begin{array}{c}\text { YTS } \\
(\mathrm{MPa})\end{array}$ & $\begin{array}{c}d \\
(\mathrm{~mm})\end{array}$ & CL & z & $\begin{array}{r}\text { Price } \\
(\$)\end{array}$ & $\begin{array}{c}\text { SD } \\
(\mathrm{mm})\end{array}$ & $\begin{array}{r}\text { Helx } \\
\text { angle }\end{array}$ & $l a$ & $c a$ \\
\hline 1 & Face mill & Carbide & & 50 & 2 & 6 & 49.50 & 25 & 15 & 45 & 5 \\
2 & Corner mill & HSS & 1035 & 10 & 6 & 4 & 7.55 & 10 & 45 & 0 & 5 \\
3 & Pocket mill & HSS & 1035 & 12 & 5 & 4 & 7.55 & 10 & 45 & 0 & 5 \\
\hline
\end{tabular}

The case study above requires multi-tool operations. The cost of the unit is solved using the Nelder-Mead Simplex method. Case Study 1 is used to compare the handbook optimal values [6] to the optimized values in other papers[7]. The five operations of Case Study 1 is represented in the following Figures 4.2, 4.3, 4.4, 4.5, and 4.6. The first operation performs a snake pattern changing direction four times. The face mill operation uses half of the radial depth of cut. For operation one, the radial depth of cut would be $25 \mathrm{~mm}$. The $K$ distance traveled would have been $450 \mathrm{~mm}$. The drill bit would move $25 \mathrm{~mm}$ passed the edge and then move $50 \mathrm{~mm}$ passed the exit cut. 


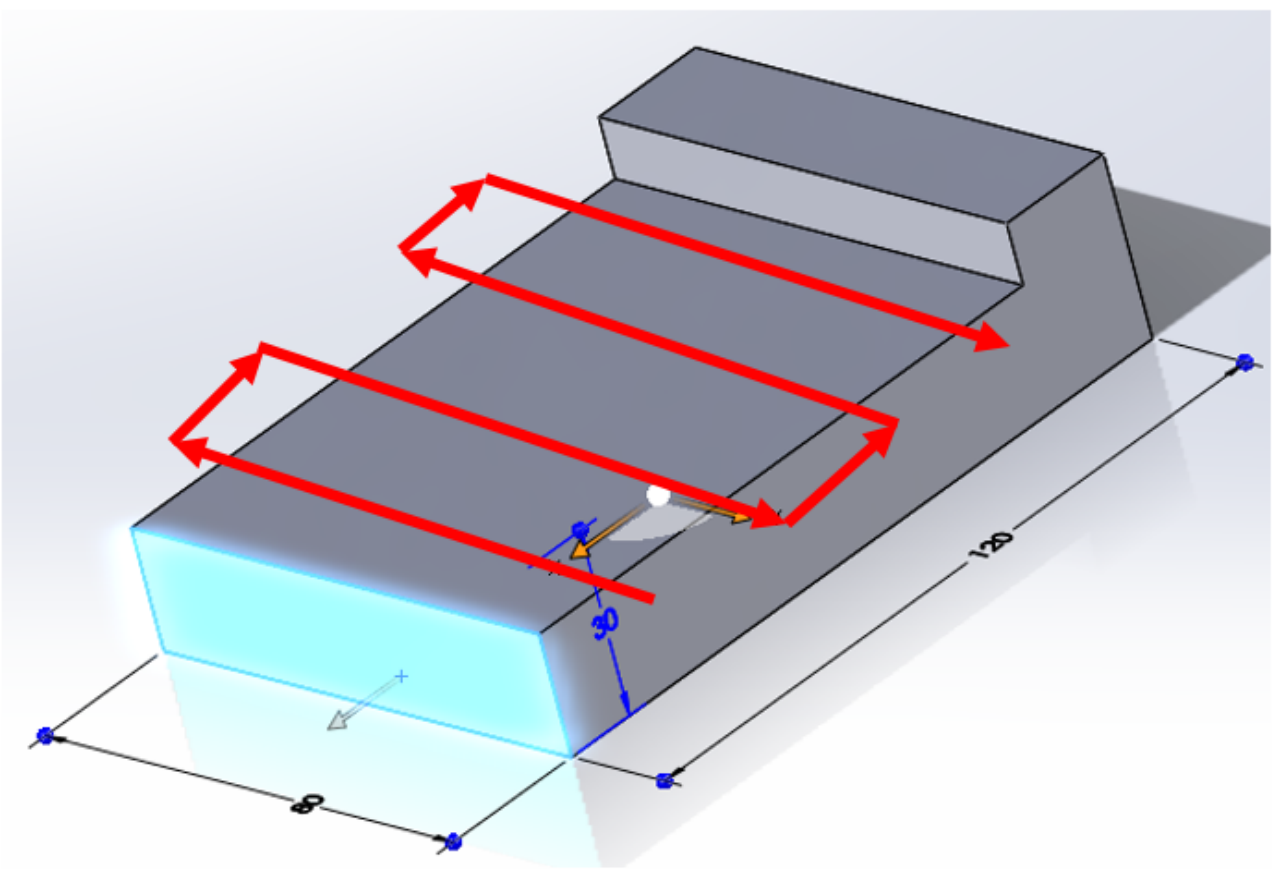

Figure 4.2: Case study 1: Operation one.

The second operational smooth out the edges in the upper sides, where the face mill just cut. Operation two makes the corner even more pronounced on the upper rail. A smooth finish is a requirement of a fit feature. The distance traveled is $90 \mathrm{~mm}$. It starts half way between one width and then moves all the way around until the next halfway point. 


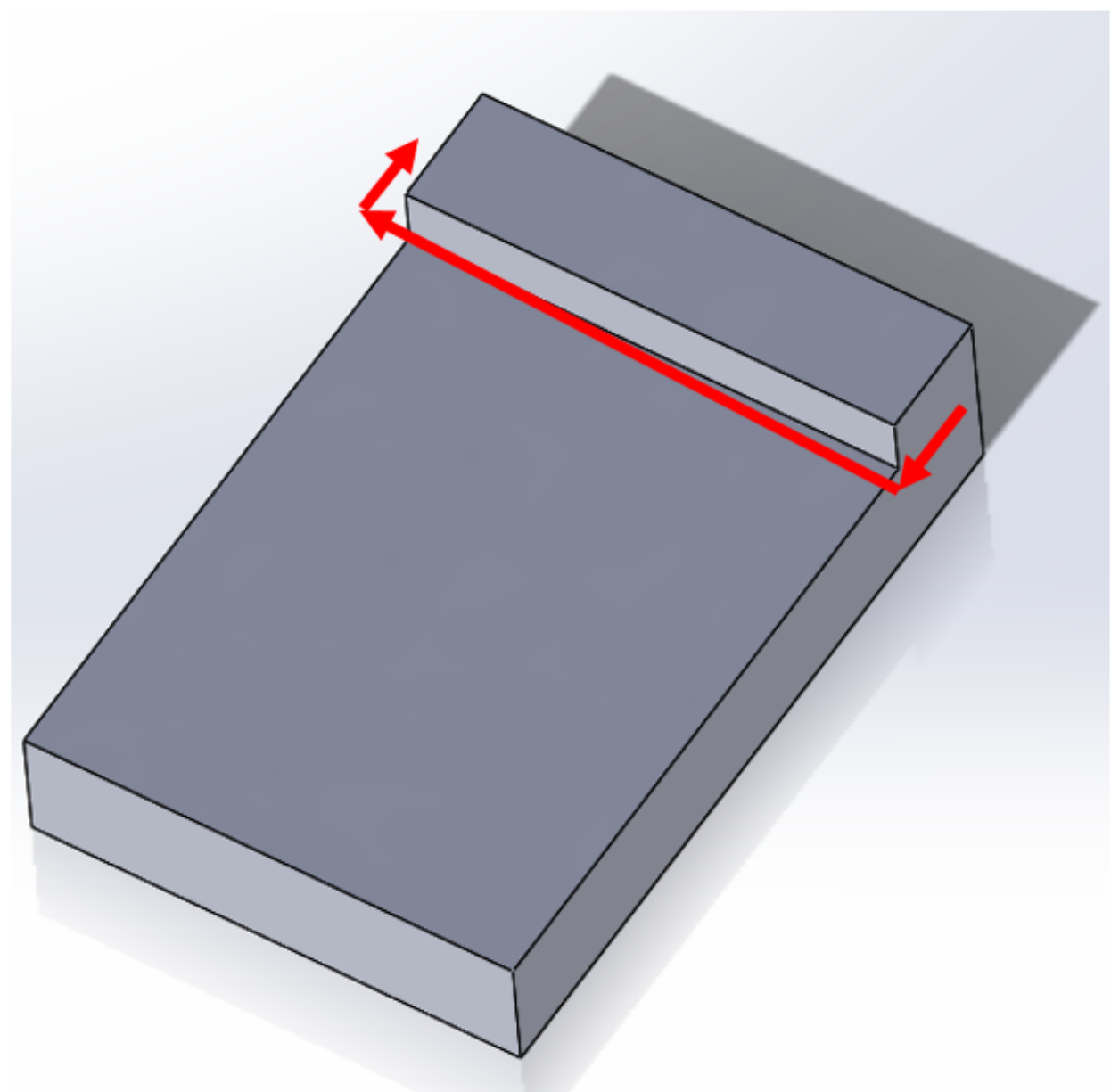

Figure 4.3: Case study 1: Operation two.

Operation three creates a pocket in the center. The pocket operation starts on one end and then makes a snake formation. The distance traveled is $450 \mathrm{~mm}$. The pocket leaves a rail inside. 


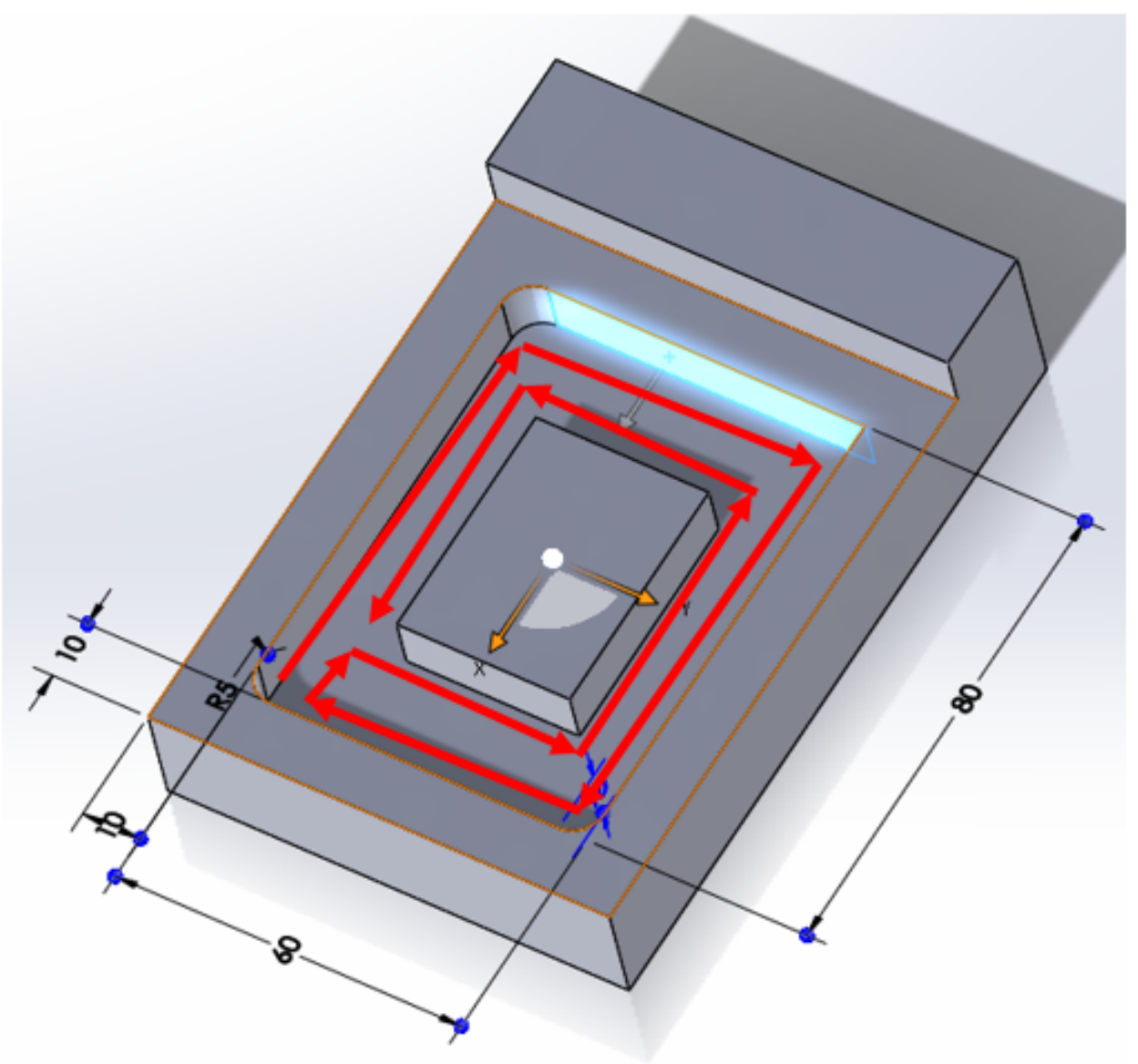

Figure 4.4: Case study 1: Operation three.

Operation four creates another slot inside the rail. The slot is made by going over the corners six times. 


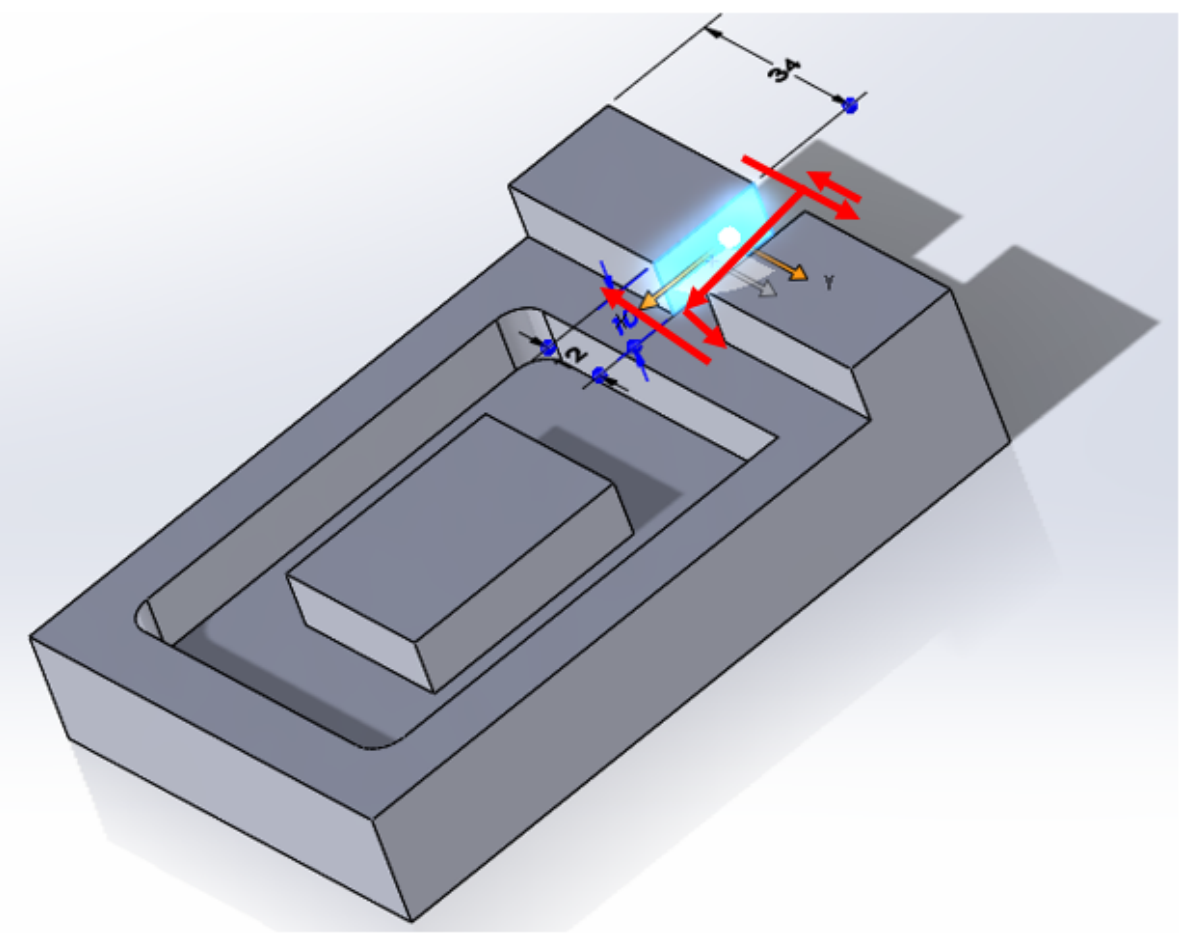

Figure 4.5: Case study 1: Operation four.

The last operation creates the slot on the rail inside the pocket. The slot is $20 \mathrm{~mm}$ wide and the same height as the rail before the slot. The depth of the cut is $5 \mathrm{~mm}$, leaving some space between the surface of pocket operation and face mill operation. 


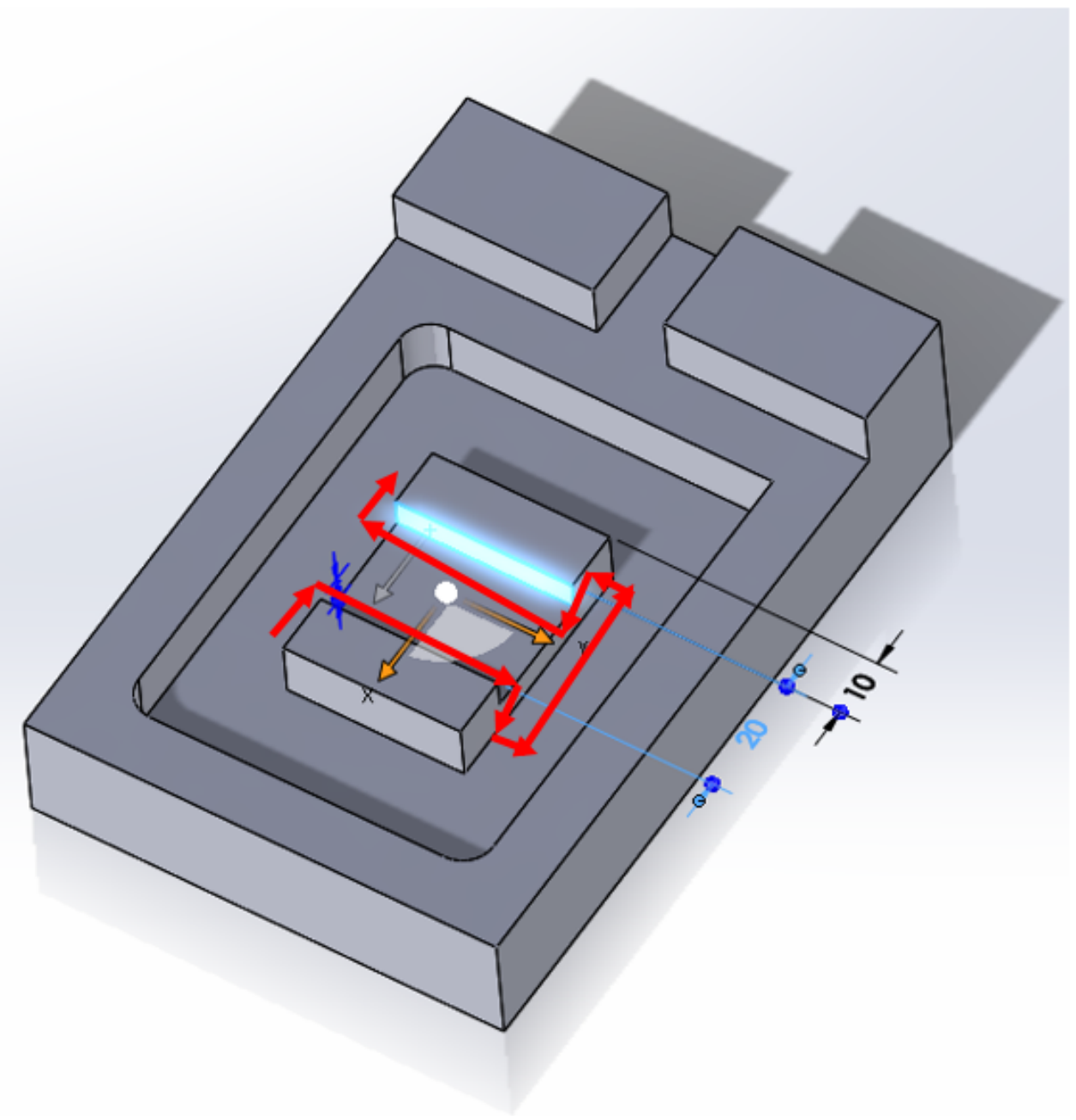

Figure 4.6: Case study 1: Operation five.

\subsection{Case study 2}

Case study 2 is done in order to get an impression on how easy it is to swap operation and consequently, the impact. Using the journal bearing sub from PSAS NSR Figure 4.7. the required tool parameters from Table 4.5 are kept the same. The initial guess 
is one that is within the feasible range.

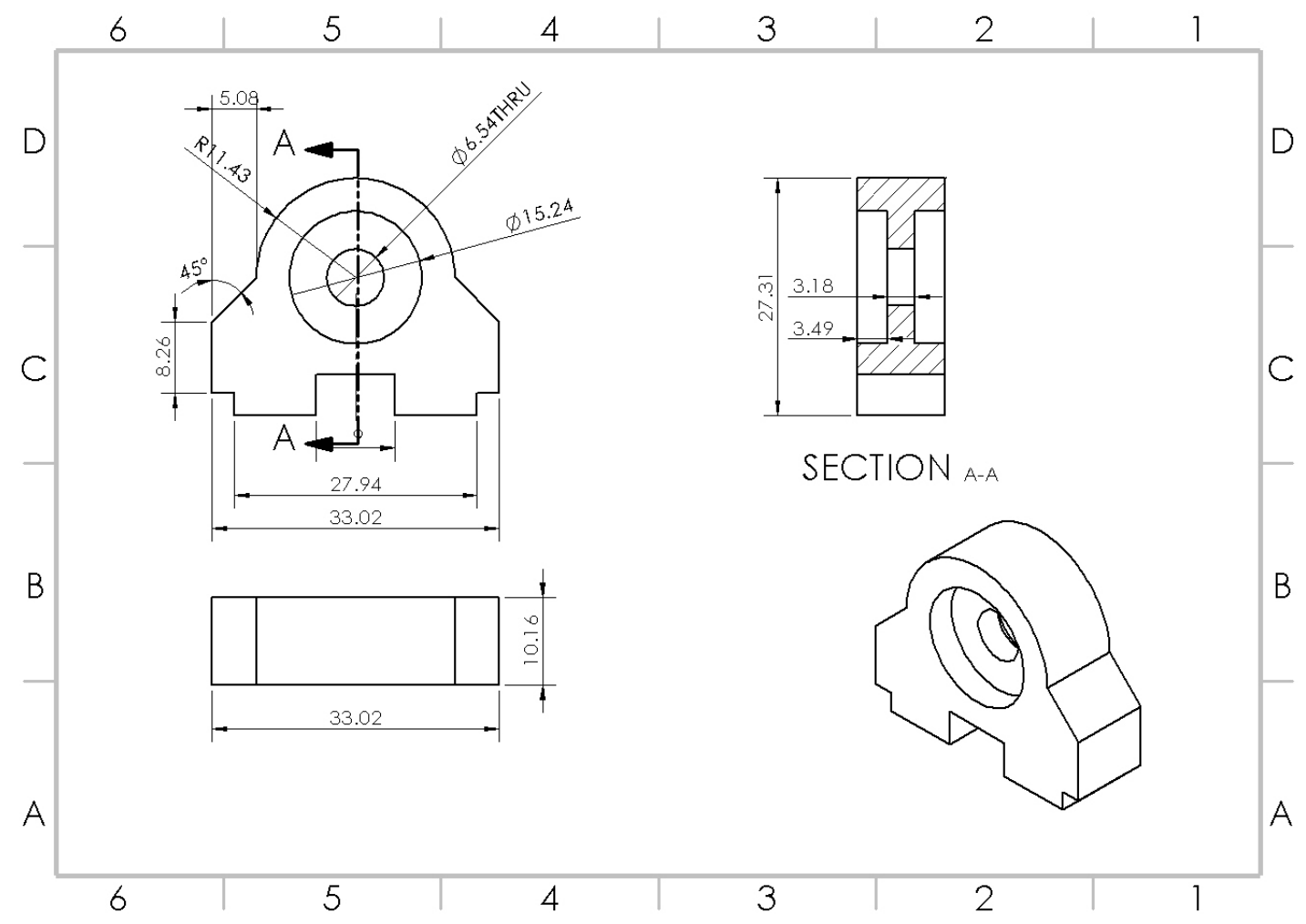

Figure 4.7: Drawing of case study 2. 
Table 4.5: Tools data parameters Case study 2.

\begin{tabular}{lll}
\hline$S p$ & $=\$ 25$ \\
$c_{\text {mat }}$ & $=\$ 0.50$ \\
$c_{o}$ & $=$ & $\$ 1.45$ per min \\
$c_{1}$ & $=$ & $\$ 0.45$ per min \\
$t_{s}$ & $=$ & $2 \mathrm{~min}$ \\
$t_{c t}$ & $=$ & $0.5 \mathrm{~min}$ \\
$C$ & $=$ & 33.98 for HSS tools \\
$w$ & $=$ & 0.28 \\
$C$ & $=$ & 100.05 for carbide \\
$K_{p}$ & $=$ & tool \\
$W$ & $=$ & 1.24 \\
$n$ & $=$ & 0.15 for HSS tools \\
$n$ & $=$ & 0.3 for carbide tool \\
$g$ & $=$ & 0.14 \\
\hline
\end{tabular}

Table 4.6: Required machining operation for Case study 2.

\begin{tabular}{clcrrr}
\hline $\begin{array}{c}\text { Operation } \\
\text { No. }\end{array}$ & $\begin{array}{l}\text { Operation } \\
\text { Type }\end{array}$ & $\begin{array}{c}\text { Tool } \\
\text { Number }\end{array}$ & $a(\mathrm{~mm})$ & $K(\mathrm{~mm})$ & $R_{a}(\mu \mathrm{m})$ \\
\hline 1 & Face milling & 1 & 10 & 50 & 2 \\
2 & Corner milling & 2 & 10 & 50 & 2 \\
3 & Slot milling & 2 & 5 & 52 & 5 \\
4 & Pocket milling & 3 & 10 & 40 & 2 \\
5 & End milling & 3 & 10 & 50 & 5 \\
6 & Hole milling & 4 & 7 & 5 & 1 \\
7 & Hole milling & 5 & 3.2 & 1.5 & 1 \\
\hline
\end{tabular}


Table 4.7: Tools data Case study 2.

\begin{tabular}{cccccccrcrrr}
\hline $\begin{array}{c}\text { Tool } \\
\text { No }\end{array}$ & $\begin{array}{c}\text { Tool } \\
\text { Type }\end{array}$ & Quality & $\begin{array}{c}\text { YTS } \\
(\mathrm{MPa})\end{array}$ & $\begin{array}{c}d \\
(\mathrm{~mm})\end{array}$ & CL & z & $\begin{array}{r}\text { Price } \\
(\$)\end{array}$ & $\begin{array}{c}\text { SD } \\
(\mathrm{mm})\end{array}$ & $\begin{array}{r}\text { Helx } \\
\text { angle }\end{array}$ & $l a$ & $c a$ \\
\hline 1 & Face mill & Carbide & & 50 & 2 & 6 & 49.50 & 25 & 15 & 45 & 5 \\
2 & Corner mill & HSS & 1035 & 8 & 6 & 4 & 7.55 & 10 & 45 & 0 & 5 \\
3 & Pocket mill & HSS & 1035 & 10 & 5 & 4 & 7.55 & 10 & 45 & 0 & 5 \\
4 & Drill mill & HSS & 1035 & 10 & 5 & 4 & 16.50 & 10 & 45 & 0 & 5 \\
5 & Drill mill & HSS & 1035 & 5 & 5 & 4 & 9.99 & 10 & 45 & 0 & 5 \\
\hline
\end{tabular}




\section{Chapter 5: Results}

\subsection{Validating the objective equation}

Validating the objective equation is done by comparing the inputs of other optimal solutions. The following tables show the objective equation is designed exactly like the other researchers. In many calculated inputs the error was less than $1 \%$ as seen in Table 5.1 and Table 5.2. However, some discrepancies are seen below.

Validating the solution is very important that it confirms the method of solving the of evaluating the objective equation is all the same. The validation of the objective equation allows a general foundation for building the exterior penalty function and the Nelder-Mead Simplex method. Once the objective function and penalty function is validated, sensitivity studies can be conducted. Sensitivity studies provide insight on possible improvements and of how big of an impact other parameters are. The objective function is constructed in the optimization model section.

Table 5.1: Validating the ability to calculate the correct cost unit $c_{u}$.

\begin{tabular}{llll}
\hline Methods & $\begin{array}{l}\text { Known } \\
(\$)\end{array}$ & $\begin{array}{l}\text { Calculated } c_{u} \\
(\$)\end{array}$ & Error \\
\hline The method of feasible direction[7] & 11.350 & 11.654 & $2.6 \%$ \\
GA[1] & 9.401 & 9.4023 & $0.5 \%$ \\
CACO[1] & 10.202 & 10.202 & $0 \%$ \\
Tabu search [1] & 11.295 & 11.292 & $0.03 \%$ \\
Particle Swarm optimization [1] & 9.316 & 9.316 & $0 \%$ \\
\hline
\end{tabular}


Table 5.2: Validating the ability to calculate the correct time unit $t_{u}$.

\begin{tabular}{llll}
\hline Method & $\begin{array}{l}\text { Known } t_{u} \\
\text { (minute) }\end{array}$ & $\begin{array}{l}\text { Calculate } t_{u} \\
\text { (minute) }\end{array}$ & Error \\
\hline The method of feasible direction[7] & 5.48 & 5.478 & $0.04 \%$ \\
GA[1] & 4.229 & 4.230 & $0.01 \%$ \\
CACO[1] & 5.438 & 4.657 & $16.8 \%$ \\
Tabu[1] & 4.231 & 4.230 & $0.02 \%$ \\
Particle Swarm optimization[1] & 4.089 & 4.089 & $0 \%$ \\
\hline
\end{tabular}

\subsection{Validating the penalty function}

While verifying the objective equation proved to be inside the feasible area[7], verifying the penalty function was not as simple. For the original paper/citetolouei-tad, the power value of the end mill for operation four and five with tool number three, the research paper used the wrong diameter. When the diameter is set to $10 \mathrm{~mm}$, the power equation is equal to $8.01 \mathrm{~kW}$ for operation four and $6.67 \mathrm{~kW}$ for operation five. When the diameter is set to $12 \mathrm{~mm}$ the power equation, the power equal to 6.67 $\mathrm{kW}$ for operation four, and $4.27 \mathrm{~kW}$ for operation five. The research paper[7] states the power value at optimal solution is $8.03 \mathrm{~kW}$. For the remainder of this study, the assumption is that the diameter should have been 12 and the power constant should have been $6.67 \mathrm{~kW}$ with the current optimization parameters.

Another issue that was not easily understood was the radial depth of cut is half of the diameter for operation one, face milling. This is a common practice in machining but not obvious from just reading. 
Lastly, the surface finish uses the wrong equation from the original paper[7] for operation two and three. Operation two and three is corner milling and pocket milling, which uses the end mill tool number two. The paper[7] states that plain milling and end milling could be represented by $R_{a}=\frac{318 f^{2}}{4 d}$, however when evaluating the optimal input with the plain mill equation the value is more than $93 \%$ off. The error in surface equation is considered to be a typo for face milling and that end milling tools should actually use the face mill equation $R_{a}=\frac{318 f}{\tan (l a)+\cot (c a)}$.

Table 5.3: Error from the original paper[7].

\begin{tabular}{|c|c|c|c|c|c|}
\hline \multicolumn{6}{|c|}{ Power constraint, wrong diameter used } \\
\hline & Power $(k W)$ & $\mathrm{d}=10(\mathrm{~mm})$ & Error & $\mathrm{d}=12(\mathrm{~mm})$ & Error \\
\hline Operation four & 8.03 & 8.01 & $0.25 \%$ & 6.67 & $16.94 \%$ \\
\hline Operation five & 5.17 & 5.13 & $0.77 \%$ & 4.27 & $17.41 \%$ \\
\hline \multicolumn{6}{|c|}{ Radial depth of cut is half } \\
\hline & $a_{\text {rad }}(\mathrm{mm})$ & $a_{\text {rad }}=\frac{d}{2}(\mathrm{~mm})$ & Error & $a_{r a d}=d(m m)$ & Error \\
\hline Operation one & 8.5 & 8.46 & $0.44 \%$ & 16.93 & $99.12 \%$ \\
\hline \multicolumn{6}{|c|}{ Surface finish uses the wrong equation from paper [7] } \\
\hline & $R_{a}(\mu m)$ & $R_{a}=\frac{318 f}{\tan (l a)+\cot (c a)}(\mu m)$ & Error & $R_{a}=\frac{318 f^{2}}{4 d}(\mu m)$ & Error \\
\hline Operation two & 5.96 & 5.95 & $0.10 \%$ & 0.36 & $93.89 \%$ \\
\hline Operation three & 4.99 & 4.98 & $0.20 \%$ & 0.25 & $94.90 \%$ \\
\hline
\end{tabular}

As seen below in Table 5.4 the following methods violated the original power constraint of $8.5 \mathrm{~kW}$ that Table 4.1 stated. 


\subsection{Constraint violation}

Table 5.4: Power constraints are violated in the genetic methods for operation one and three.

\begin{tabular}{llll}
\hline Methods & $V_{o}\left(\frac{\mathrm{m}}{\mathrm{min}}\right)$ & $f_{o}\left(\frac{\mathrm{mm}}{\text { tooth }}\right)$ & Power $(\mathrm{kW})$ \\
\hline Handbook [6] Operation one & 80.000 & 0.078 & 6.693 \\
Handbook [6] Operation three & 20.000 & 0.013 & 0.266 \\
Method of feasible direction[7] Operation one & 101.150 & 0.078 & 8.500 \\
Method of feasible direction[7] Operation three & 55.020 & 0.179 & 5.990 \\
Present study (NM method) Operation one & 51.448 & 0.183 & 8.500 \\
Present study (NM method) Operation three & 48.819 & 0.184 & 5.415 \\
GA [1] Operation one & 119.941 & 0.400 & 18.554 \\
CACO [1] Operation one & 117.474 & 0.163 & 8.862 \\
Tabu search [1] Operation one & 80.469 & 0.398 & 12.398 \\
Tabu search [1] Operation three & 62.522 & 0.354 & 11.695 \\
Particle Swarm optimization [1] Operation one & 119.367 & 0.400 & 18.466 \\
\hline
\end{tabular}

When comparing the optimal solutions of operation one, the present study optimal solution is reasonable when compared to ones reported in[7] and the handbook[6]. The handbook solutions are conservative by nature as it is a recommendation. In the reference[7], the cutting speed for operation one was increased from the initial guess $80 \frac{\mathrm{m}}{\text { minute }}$ to $101.15 \frac{\mathrm{mm}}{\text { tooth }}$. The feed rate remained the same. In the present study, an initial guess of $\mathrm{V}=20 \frac{\mathrm{m}}{\text { minute }}$ and $\mathrm{f}=0.09 \frac{\mathrm{mm}}{\text { tooth }}$ was chosen. These values were suggested by the handbook for most milling operations. For operation one, the optimal solution $50.8 \frac{\mathrm{m}}{\text { minute }}$ and $0.186 \frac{\mathrm{mm}}{\text { tooth }}$, obtained by the present study were better than $101.15 \frac{m}{\text { minute }}$ and $0.078 \frac{\mathrm{mm}}{\text { tooth }}$ found in the reference[7]. The profit rate calculated by the present study was $9.8 \%$ higher for operation one and $6.5 \%$ for overall unit 
when compared to reference[7]. The upper limits for cutting speed was set to $120 \frac{\mathrm{m}}{\mathrm{min}}$ and $0.4 \frac{\mathrm{mm}}{\text { tooth }}$. In the present study both design variables are in the middle whereas the original paper[7] only one design variable is in the middle and the other design variable is near the maximum. The group of Genetic Algorithms methods have their design variables maxed on both of them. Maxing both design variables has to lead to power constraint being violated when the handbook recommends only one design variable to maxed.

\subsection{Optimal design variables: Case study 1}

Assuming the same errors as the original paper, the optimal solution of the present study had a better profit rate. The improvement on profit rate was due to the Nelder-Mead Simplex method parameters and the initial guess. The Nelder-Mead method started with the standard universal parameters $\alpha=1, \gamma=2, \rho=0.5$, and $\sigma=0.5[4]$. After some fine tuning the present study was able to arrive a better result, using the following Simplex parameters $\alpha=0.75, \beta=0.8 \gamma=2.45, \rho=0.4$, and $\sigma=0.4$.

The initial guess allowed the Nelder-Mead Simplex Method to slow down the cutting speed and increase the feed rate instead of speeding up the cutting speed. Although the handbook recommendation was still better than the present study's initial guess, a better optimal solution was found. 
Table 5.5: Optimal design parameters for case study one.

\begin{tabular}{llllll}
\hline $\begin{array}{l}\text { Operation number } \\
\text { No. }\end{array}$ & Operation & $\begin{array}{l}\text { Tool } \\
\text { Number }\end{array}$ & $\begin{array}{l}a \\
(\mathrm{~mm})\end{array}$ & $\begin{array}{l}V_{o} \\
\left(\frac{m}{\mathrm{~min}}\right)\end{array}$ & $\begin{array}{l}f_{o} \\
\left(\frac{m m}{\text { tooth }}\right)\end{array}$ \\
\hline 1 & Face milling & 1 & 10 & 50.800 & 0.186 \\
2 & Corner milling & 2 & 5 & 49.880 & 0.207 \\
3 & Pocket milling & 2 & 10 & 47.997 & 0.197 \\
4 & Slot milling & 3 & 10 & 47.369 & 0.186 \\
5 & Slot milling & 3 & 5 & 46.571 & 0.176 \\
\hline & Cost unit (\$) & & & & 10.93 \\
& Time unit (minute) & & & & 5.32 \\
\hline
\end{tabular}

Optimal values from Table 5.5 compare well to optimal values[7].

\subsection{Cost after each cut: Case study 1}

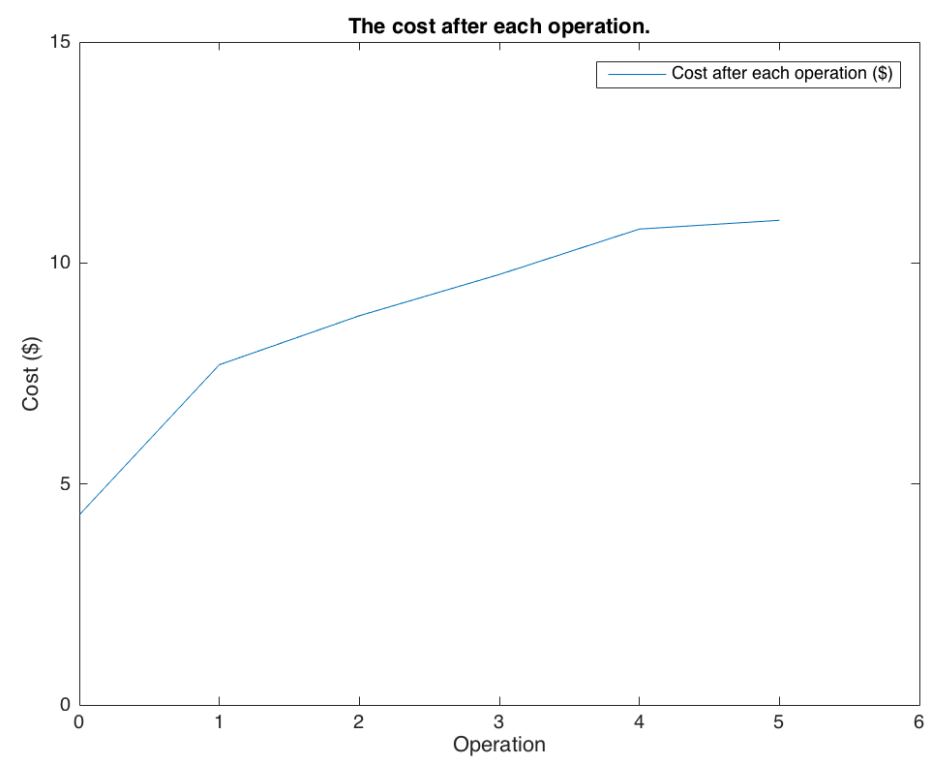

Figure 5.1: Cost after each operation in Case study 1. 
The present study noticed that the most significant cost was at the start, before any operation occurred. Then there is a slow gradual increase after the first operation in Figure 5.1 .

\subsection{Time after each cut: Case study 1}

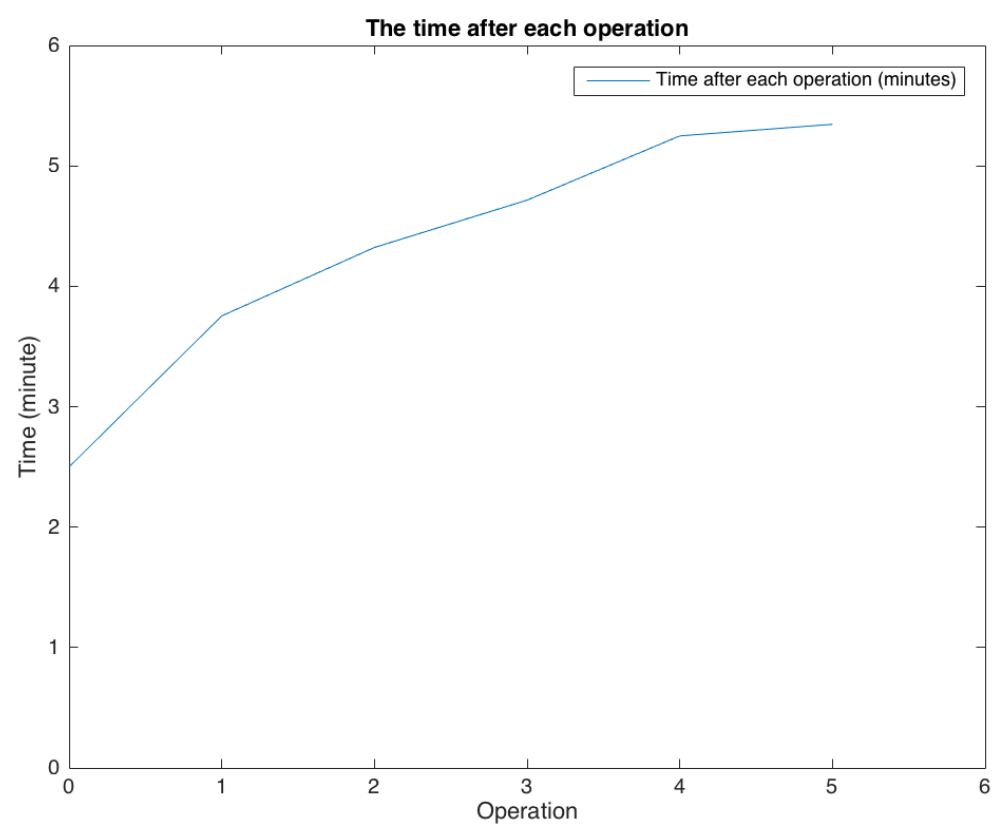

Figure 5.2: Time after each operation in Case study 1.

The present study noticed that the most significant time per tool was at the start, before any operation occurred. Then there is a slow gradual increase after the first operation in Figure 5.2 . 


\subsection{Sensitivity study}

Table 5.6: Simplex beats handbook and method of feasible direction.

\begin{tabular}{llll}
\hline Method & $\begin{array}{l}C_{u} \\
(\$)\end{array}$ & $\begin{array}{l}T_{u} \\
(\text { minute })\end{array}$ & $\begin{array}{l}P_{r} \\
\left(\frac{\$}{\text { minute }}\right)\end{array}$ \\
\hline Handbook [6] & 18.36 & 9.40 & 0.71 \\
Method of feasible direction [7] & 11.35 & 5.48 & 2.49 \\
Present study (NM method) & 10.92 & 5.32 & 2.65 \\
GA method[1] & 9.40 & 4.23 & 3.69 \\
CACO method[1] & 10.20 & 5.44 & 2.72 \\
Tabu search [1] & 11.30 & 4.23 & 3.24 \\
Particle Swarm optimization [1] & 9.32 & 4.09 & 3.85 \\
\hline
\end{tabular}

The Nelder-Mead Simplex method was not able to outperform every method but certainly able to outdo the original Method of feasible direction and what the handbook recommenders. When doing a sensitivity study of the optimal setting, the values converge to the same spot and could not move from it. When an optimal solution does not move from an initial guess it shows it is at minimum. When the initial guess is set to a minimum the group of Genetic Algorithms methods had found, they were able to improve their results slightly. However, the initial guess had already violated the constraints leading to a result that had less of a penalty applied. Without selecting a value in a feasible range the Nelder-Mead Simplex method was useless.

The Nelder-Mead Simplex method would improve on these infeasible estimates but it would still fail and terminate before it was able to move back in the feasible region. See below for an example of how the algorithm would push an optimal solution 
in the infeasible range. If the initial guess had been changed to something close to the optimal solution but still in the feasible range, the Simplex triangle would quickly converge to the same minimum. The Nelder-Mead Simplex method would have the algorithm terminate at a local minimum often and a lot of the optimal values was determinate by the initial guess. Multiple trials are required to find a solution better than the Method of feasible direction. The Nelder-Mead Simplex algorithm takes 1.78 second to run with 2586 calls to objective function and penalty function. The programming language is MATLAB. The hardware was $20152.7 \mathrm{GHz}$ Intel Core i5 processor and 8 GB $1867 \mathrm{MHz}$ DDR3 memory.

Table 5.7: When the initial guess is set at a local minimum.

\begin{tabular}{llllll}
\hline Initial & $V_{i}$ & $f_{i}$ & After & $V_{o}$ & $f_{o}$ \\
Guess & $\left(\frac{m}{m i n}\right)$ & $\left(\frac{m m}{\text { tooth }}\right)$ & initial Guess & $\left(\frac{m}{m i n}\right)$ & $\left(\frac{m m}{\text { tooth }}\right)$ \\
\hline & 101.1500 & 0.0780 & & 97.5293 & 0.0782 \\
& 63.2600 & 0.2140 & 63.9030 & 0.2157 \\
& 55.0200 & 0.1790 & 56.0067 & 0.1797 \\
& 47.4600 & 0.2480 & 48.1160 & 0.2491 \\
& 42.7200 & 0.3880 & 42.9899 & 0.3885 \\
\hline$f(x)\left(\frac{\$}{\text { minute }}\right)$ & 15.57 & & & $-3.9844 \mathrm{e}+03$ & \\
\hline
\end{tabular}

Table 5.7 shows how the Penalty function can change the objective function significantly when the inputs are altered. Each of the values in Table 5.7 had been tweaked a little bit but had not actually improved anything. The optimal values had actually made it significantly worst because they started to violate the constraints. 
When changing the cost of labor, and cost of overhead to $\$ 9.45$ a minute, it caused the cost per unit to increase but it did not actually increase the constraints.

The constraints were still set to keep the tool working for a long time. A new optimization problem occurs if the cost of labor is far more expensive than the part. The tool life does not matter as much and replacing the tool all the time is a better solution than making the tool cut slower. If the parameters in Table 4.2 are to change significantly new Nelder-Mead Simplex parameters are required and further fine tuning is necessary.

\subsection{Optimal design variables: Case study 2}

Table 5.8: Optimal design parameters for case study 2.

\begin{tabular}{clcrrc}
\hline $\begin{array}{c}\text { Operation } \\
\text { No. }\end{array}$ & Operation & $\begin{array}{c}\text { Tool } \\
\text { Number }\end{array}$ & $a(\mathrm{~mm})$ & $\begin{array}{r}V_{o} \\
\left(\frac{m}{\min }\right)\end{array}$ & $\begin{array}{c}f_{o} \\
\left(\frac{m m}{\text { tooth }}\right)\end{array}$ \\
\hline 1 & Face milling & 1 & 10 & 47.497 & 0.204 \\
2 & Corner milling & 2 & 10 & 40.278 & 0.182 \\
3 & Slot milling & 2 & 5 & 53.915 & 0.173 \\
4 & Pocket milling & 3 & 10 & 49.788 & 0.190 \\
5 & End milling & 3 & 10 & 54.082 & 0.165 \\
6 & Drill milling & 4 & 7 & 47.488 & 0.158 \\
7 & Drill milling & 5 & 3.2 & 44.982 & 0.152 \\
\hline & Cost unit $(\$)$ & & & & 10.02 \\
& Time unit (minute) & & & & 4.73 \\
& Profit rate $\left(\frac{\$}{\text { minute }}\right)$ & & & & 3.17 \\
\hline
\end{tabular}


Using the Nelder-Mead Simplex method for Case study 2 proceed similar results to Case study 2. All of the data points were close to the previous tool optimization steps. The differen between operations between studies shows the Nelder-Mead Simplex method works the way it is expected to. The tool parameters could easily be changed and new design values can be obtained.

\subsection{Cost after each cut: Case study 2}

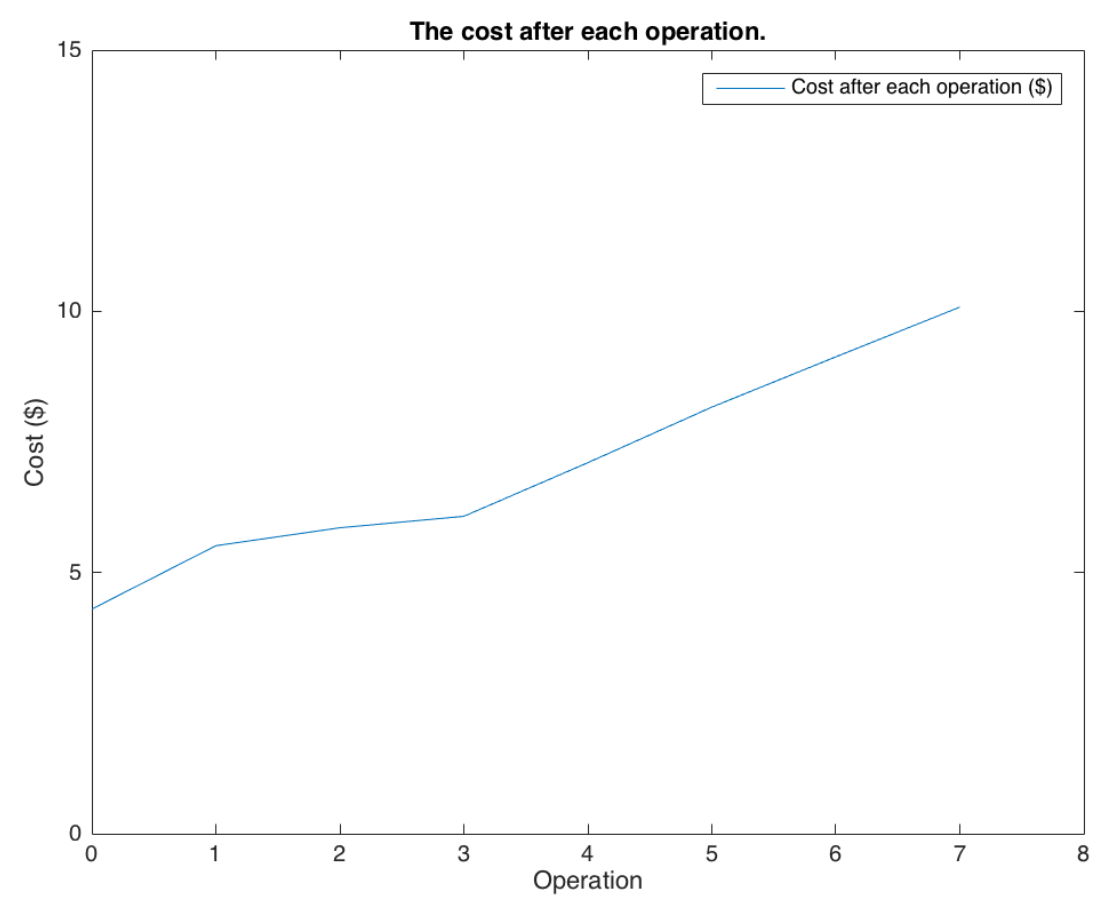

Figure 5.3: Cost after each operation in Case study 2. 


\subsection{Time after each cut: Case study 2}

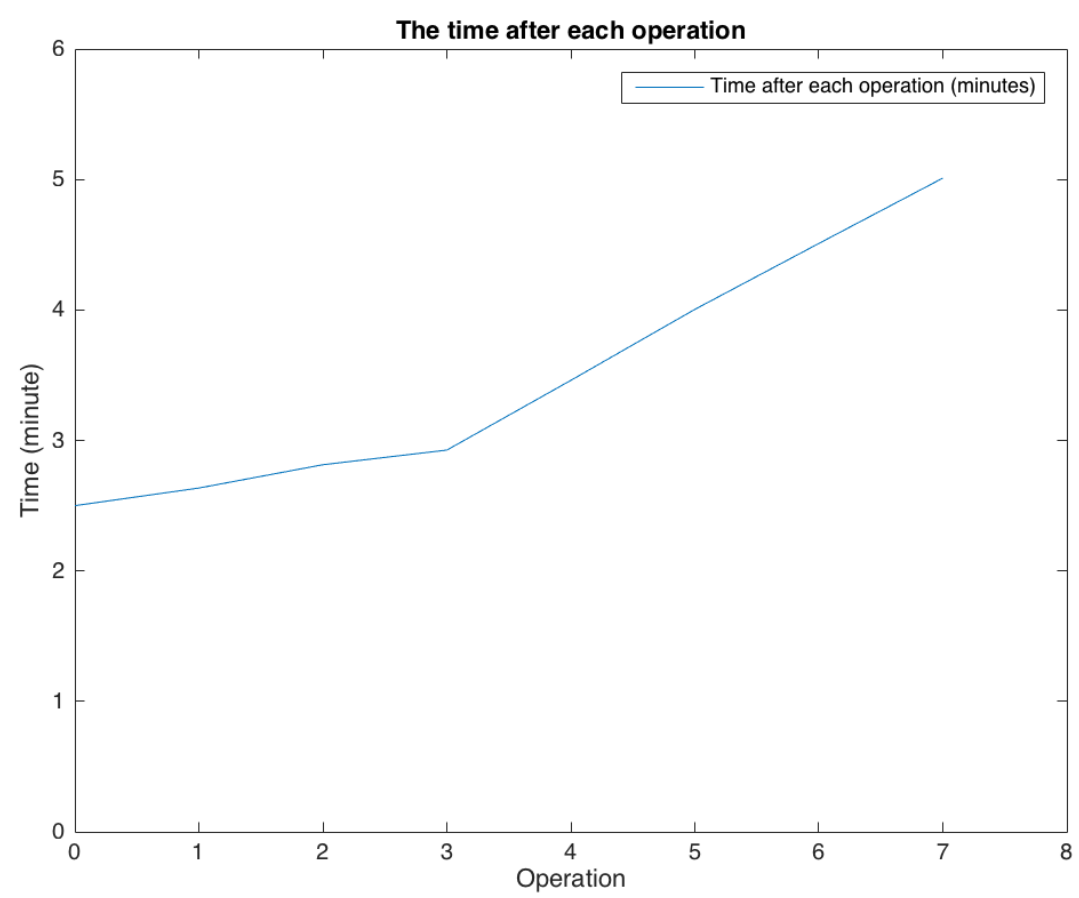

Figure 5.4: Time after each operation in Case study 2.

Both the cost and time per operation mirror each other for both case studies. In order to maximize profit, both cost and time must be minimized. This has created an equilibrium between both factors. 


\section{Chapter 6: Conclusion}

The Nelder-Mead Simplex method was able to find an optimal value better than the handbook. The initial guess became really important. If an initial guess set one close the handbook, it would begin to increase the cutting speed. If the initial guess was towards to lower end it would settle for optimal solutions in the middle. The Simplex parameters started off at the universal Simplex values but some fine tuning is required. For faster optimization the Simplex parameters are set to for loops that would compare every parameter to each other. The previous for loops for these Simplex parameters were used for an estimate for the best Simplex parameters.

Errors in the power constraint and surface finish were found in the papers [1, 7]. The particular knowledge of machining is as much if not more than the mathematical knowledge to set up the Nelder-Mead Simplex method. The Simplex variation designed by the present study showed how a new case study could be developed and did much of the preemptive white paper calculations required to go from theory to application. The new case study provided more complex tools, that were not included in the original design.

Nonetheless, the estimation for an optimal solution that will not violate the constraints is calculated extremely fast. The constraints in this objective function are the determining factor for the optimal solutions. Many of other paper's[1] optimal solution to violate the initial constraints brought by the original paper[7]. These constraints proved to be the defining factor that allowed the optimization method 
optimal solutions to converge to a reasonable solution. The Nelder-Mead Simplex method is able to improve on previous results while keeping the computation to a minimum. The success is dependent on to the algorithm's parameters and the initial guess attempted at different points. 


\section{Biography}

[1] Baskar, N., Saravanan, R., Asokan, P. and Prabhaharan, G. (2005), "Optimization of machining parameters for milling operations using non-conventional methods." International Journal Adance Manufacturing Technology, 25, 1078-1088.

[2] Kant, G. and Sangwan, K.S. (2014), "Prediction and optimization of machining parameters for minimizing power consumption and surface roughness in machining." Journal of Cleaner Production, 83, 151-164.

[3] Kronenberg, M. (1966), "Machining science and application." Pergamon Press, Oxford.

[4] Lagarias, J. C., Reeds, J. A., Wright, M.H, and Wright, P.E. (2013), "Convergence properties of the Nelder-Mead Simplex method in low dimensions." Society for Industrial and Applied Mathematics, 9, 112-147.

[5] Nelder, J. A. and Mead, R. (1965), "A Simplex method for function minimization." The Computer Journal, 7, 308-313.

[6] Machinability Data Center Technical Staff (1980), Machining Data Handbook, 3 edition, volume 1.

[7] Tolouei-Rad, M. and Bidhendi, I.M. (1996), "On the optimization of machining parameters for milling operations." International Journal Machine Manufacturing, $37,1-16$

[8] Yildiz, A. R. (2013), "Cuckoo search algorithm for the selection of optimal machining parameters in milling operations." International Journal Adance Manufacturing Technology, 64, 55-61. 